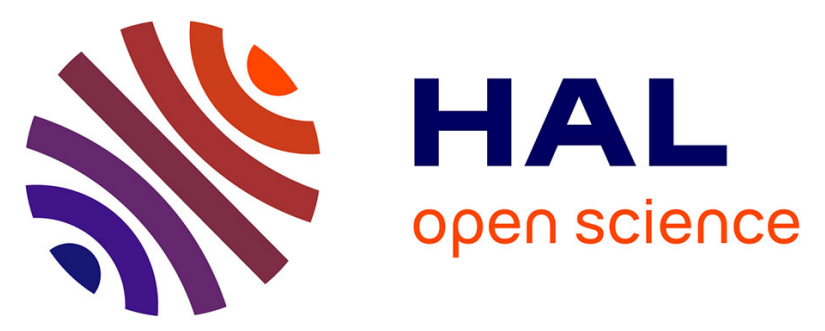

\title{
PAK3 is a key signature gene of the glioma proneural subtype and affects its proliferation, differentiation and growth
}

Nathalie Magne, Véronique Rousseau, Kévin Duarte, Sandrine Poëa-Guyon, Vincent Gleize, Alexandre Mutel, Charlotte Schmitt, Hélène Castel, Ahmed Idbaih, Emmanuelle Huillard, et al.

\section{To cite this version:}

Nathalie Magne, Véronique Rousseau, Kévin Duarte, Sandrine Poëa-Guyon, Vincent Gleize, et al.. PAK3 is a key signature gene of the glioma proneural subtype and affects its proliferation, differentiation and growth. Cellular Oncology, 2021, 44 (6), pp.1257-1271. 10.1007/s13402-021-00635-8 . hal-03439238

\section{HAL Id: hal-03439238 \\ https://hal.science/hal-03439238}

Submitted on 22 Nov 2021

HAL is a multi-disciplinary open access archive for the deposit and dissemination of scientific research documents, whether they are published or not. The documents may come from teaching and research institutions in France or abroad, or from public or private research centers.
L'archive ouverte pluridisciplinaire HAL, est destinée au dépôt et à la diffusion de documents scientifiques de niveau recherche, publiés ou non, émanant des établissements d'enseignement et de recherche français ou étrangers, des laboratoires publics ou privés. 


\section{PAK3 is a key signature gene of the glioma proneural subtype 3 and affects its proliferation, differentiation and growth}

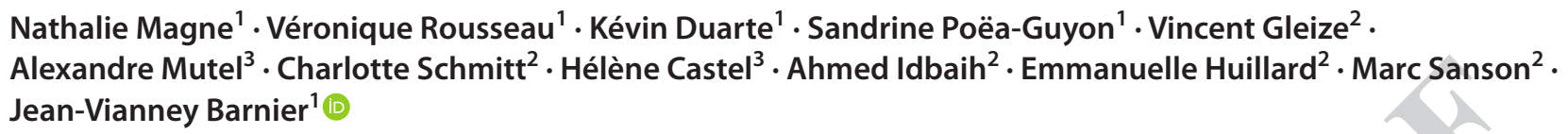

\section{Abstract}

Purpose Gliomas are the most lethal adult primary brain cancers. Recent advances in their molecular characterization have contributed to a better understanding of their pathophysiology, but there is still a need to identify key genes controlling glioma cell proliferation and differentiation. The p21-activated kinases PAK1 and PAK2 play essential roles in cell division and brain development and are well-known oncogenes. In contrast, the role of PAK3 in cancer is poorly understood. It is known, however that this gene is involved in brain ontogenesis and has been identified as a gene of the proneural subtype signature in glioblastomas.

Methods To better understand the role of PAK kinases in the pathophysiology of gliomas, we conducted expression analyses by querying multiple gene expression databases and analyzing primary human glioma samples. We next studied PAK3 expression upon differentiation in patient-derived cell lines (PDCLs) and the effects of PAK3 inhibition by lentiviral-mediated shRNA on glioma cell proliferation, differentiation and tumor growth.

Results We show that contrary to $P A K 1$ and $P A K 2$, high $P A K 3$ expression positively correlates with a longer survival of glioma patients. We also found that $P A K 3$ displays differential expression patterns between glioma sub-groups with a higher expression in 1p/19q-codeleted oligodendrogliomas, and is highly expressed in tumors and PDCLs of the proneural subtype. In PDCLs, high PAK3 expression negatively correlated with proliferation and positively correlated with neuronal differentiation. Inhibition of $P A K 3$ expression increased PDCL proliferation and glioma tumor growth in nude mice.

Conclusions Our results indicate that $P A K 3$ plays a unique role among PAKs in glioma development and may represent a potential therapeutic target.

Keywords Gliomas $\cdot$ Proneural signature $\cdot$ p21-activated kinase $\cdot$ Patient-derived cell line $\cdot$ Proliferation and neuronal differentiation · Glioma tumor growth

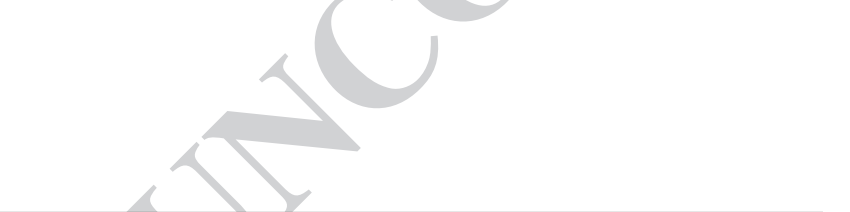

Jean-Vianney Barnier

jean-vianney.barnier@cnrs.fr

1 Université Paris-Saclay, CNRS, Institut des Neurosciences Paris-Saclay, 91190 Gif-sur-Yvette, France

2 Sorbonne Université, Inserm, CNRS, UMR S 1127, Institut du Cerveau, ICM, AP-HP, Hôpitaux Universitaires La Pitié Salpêtrière - Charles Foix, Service de Neurologie 2-Mazarin, 75013 Paris, France

3 Normandie Univ, UNIROUEN, INSERM, U1239, Laboratoire Différenciation Et Communication Neuronale Et Neuroendocrine, Institut de Recherche Et D'Innovation Biomédicale de Normandie, 76000 Rouen, France

\section{Introduction}

Diffuse gliomas, including glioblastomas (GBMs), are the most common malignant primary brain tumors and contain diverse populations of cells ranging from highly tumorigenic stem-like cells to more differentiated cells $[1,2]$. Molecular studies have related genetic alterations, gene expression profiles, and DNA methylation signatures to distinct glioma subtypes with prognostic value [3-7]. Those studies have also led to the deciphering of key signaling pathways involved in glioma biology, and inlightened the altered differentiation and multipotency of the tumor cells [8]. They also helped to characterize potential therapeutic targets relevant for each subtype of

\begin{tabular}{|l|l|l|l|l}
\hline Journal : Large 13402 & Article No: $\mathbf{6 3 5}$ & Pages : 16 & MS Code : 635 & Dispatch : 6-9-2021 \\
\hline
\end{tabular}


glioma. p21-activated kinases (PAKs) play important functional roles in neuronal differentiation and cancer biology. The three group I PAKs (PAK1, PAK2 and PAK3) form a small gene family encoding the main effectors of the Rac and Cdc42 GTPases, which play crucial roles in cell proliferation and migration [9]. These kinases are expressed in the developing and adult brain where they have unique functions during brain development [10]. PAKl regulates cortical development via the control of progenitor cell proliferation and neuronal differentiation [11]. PAK2 is an effector of the Rheb/TSC complexes in benign tuberous sclerosis in neuronal tissues [12].

Within this family, PAK3 may have unique signaling properties since its mutations have been found to be responsible for several neurological disorders including intellectual disability [10]. PAK3 is involved in brain development, regulating cell cycle exit of neuronal precursors during primary neurogenesis, and in neurite outgrowth and neuronal differentiation during telencephalon ontogenesis [13-15]. $P A K 3$ also regulates oligodendroglial lineage rate specification [16] $P A K 1$ and $P A K 2$ are oncogenes often found to be overexpressed or activated in different cancers such as breast and colon cancer [17, 18]. Their over-activation and over-expression favour cell proliferation, inhibit apoptosis, enhance invasion and metastasis, and sustain angiogenesis, all cell functions that trigger oncogenesis [17]. In contrast, PAK3 overexpression or mutation have only been associated with adrenocorticotropic hormone-secreting tumors [19]. It has also been found, however, that this gene belongs to the proneural transcriptomic signature in glioblastomas (GBMs) $[6,20]$.

As yet, the role of $P A K s$ in gliomas is scarcely described in the literature [21]. To investigate this further, we analyzed group PAK1-3 expression according to histological and molecular criteria in a well-characterized patient cohort and in data deposited in public cancer databases. Contrary to $P A K 1$ and $P A K 2$, high $P A K 3$ expression was found to be positively correlated with a longer patient survival. We also found that $P A K 3$ was differentially expressed between glioma subgroups, with a higher expression in $1 \mathrm{p} / 19 \mathrm{q}$-codeleted oligodendrogliomas. Comparison of $P A K$ expression in GBM patient-derived cell lines (PDCLs) and in their parental tumors indicated that $P A K 3$ expression may serve as one of the more reliable markers of the proneural subtype. In PDCLs, increasing PAK3 expression upon a set of differentiation paradigms was correlated with those of neuronal markers. Interestingly, short hairpin RNA-mediated inhibition of PAK3 expression increased PDCL proliferation and astrocytic marker expression, and also accelerated in vivo tumor growth. Together, these data indicate that $P A K 1-2$ and $P A K 3$ play different roles in the pathophysiology of gliomas. $P A K 3$ exhibits an inhibitory role in glioma tumor growth and may be of potential interest for glioma therapy.

\section{Materials and methods}

\subsection{In silico tumor database analysis}

RNA-seq data were obtained from the transcriptomic database of Zhang et al. [22] and are expressed in FPKM (Fragments Per Kilobase of exon per Million reads mapped) values. RNAs were extracted from different cell types purified from the postnatal mouse cerebral cortex (http://web.stanf ord.edu/group/barres_lab/brain_rnaseq.html). Gene expression analyses from primary tumors were performed employing the Academic Medical Center (AMC) database, using the R2 genomics analysis and visualization platform (http:// r2.amc.nl) and across different tumor datasets for each analyzed gene [23]. Kaplan-Meier survival curves of patients were derived from the Tumor Glioma-French-284 -dataset, composed of 276 glioma samples of all histologies and 8 control samples [24]. Samples were sorted according to the expression of each $P A K$ and divided into two groups on the basis of a cutoff expression value giving the higher probability of confidence, using the log-rank test with Bonferroni correction for multiple comparisons. The clinical and molecular data of lower grade gliomas (LGGs) and GBM samples for this study were downloaded from The Cancer Genome Atlas database (https://tcga-data.nci.nih.gov/docs/publicatio ns/tcga/) generated by the TCGA Research Network (http:// cancergenome.nih.gov/), firstly in 2014 and subsequently in February 2016 (cancer genome). mRNA expression levels of PAK1 and PAK3 were obtained from RNAseq analyses using Illumina TruSeq Kit Paired-end Sequencing on an Illumina HiSeq2000. Detection of somatic variants (IDHmut) from TCGA whole-exome sequencing and RNAseq data was performed using RADIA [25]. The mRNA levels were represented as "normalized count" corresponding to a transformation of the "raw_count". For each gene of interest, all "raw_count" values were divided by the 75th percentile of the column patient (after removing zeros) and multiplied by 1000 .

\subsection{Glioma sample analyses}

Patient samples (from the OncoNeuroTek tissue bank) and informed consent, RNA extraction and gene expression analyses have been described before [26].

\subsection{GBM cell culture, shRNA and lentiviral infection}

Primary sphere cultures were initially derived from patient tumors as described before [27]. Glioblastoma-derived spheres were cultured in DMEM/F12 medium supplemented with penicillin/streptomycin and B27 (Life Technologies), 
referred to as basal medium, supplemented with EGF (20 ng/ $\mathrm{ml}$; Peprotech) and FGF (20 ng/ml; Miltenyi), referred to as proliferative medium. Spheres were dissociated using StemPro Accutase (Life technologies) when they reached a size of 100-200 $\mu \mathrm{m}$. For cell growth analysis, dissociated cells were seeded at $5 \times 10^{4}$ cells $/ \mathrm{ml}$ in triplicates, and on day 1 , 4 and 7, live cells from dissociated spheres were counted. Viability was tested by Trypan blue exclusion. For differentiation experiments, single-cell suspensions were seeded on a laminin substrate $(10 \mu \mathrm{g} / \mathrm{ml}$; Life technologies $)$ in the proliferative medium, as described before [28]. Twenty-four hours later, the medium was replaced with basal medium containing $0.5 \%$ fetal calf serum, or in some experiments, with basal medium containing Bone Morphological Protein-4 (BMP-4, $10 \mathrm{ng} / \mathrm{ml}$, Peprotech) or all-trans-retinoic acid (ATRA, $10 \mu \mathrm{M}$, Sigma). For $P A K 3$ expression inhibition, viral particles containing TRC human PAK3 shRNA (Thermo Scientific) cloned in the pLKO.1 lentiviral vector were produced at the ICM Vectorology platform and used to transduce PDCLs. After puromycin selection, the efficiency of $P A K 3$ expression inhibition was analyzed in proliferative and differentiative conditions by qRT-PCR.

\subsection{Quantitative real-time PCR (qRT-PCR)}

Total RNA was isolated from cells using TRIzol Reagent (Life Technologies) according to the manufacturer's protocol. RNA quality analysis was performed using a Bio-Rad's Experion system and nanodrop, and cDNAs were generated from $0.5 \mu \mathrm{g}$ mRNAs using an iScript Reverse Transcription Supermix (Biorad). Real-time PCR was performed on a CFX96 Touch Real-Time PCR Detection System (Biorad) using a SsoAdvanced Universal SYBRGreen Supermix (Biorad), Primers were designed by retrieving nucleotide sequences from the NCBI gene database using the Primer3Plus program (http://www.bioinformatics.nl/cgi-bin/prime r3plus/primer3plus.cgi/). Gene-specific primers were synthesized by Eurofins Genomics and their sequences are listed in Supplementary Materials. Samples were amplified in triplicate and relative copy numbers were determined using the comparative $\triangle \triangle \mathrm{Ct}$ method, with PPIA and GAPDH as normalization genes, and expression in a human embryonic brain mRNA sample as exogenous reference (Clinisciences).

\subsection{Western blotting}

For Western blot analysis, protein samples $(10 \mu \mathrm{g})$ were separated by $10 \%$ SDS-PAGE and transferred to PVDF membranes (Millipore), as previously described [29]. Immunoblot analyses were performed using antibodies described in Supplementary Materials. Immunodetection was performed using a Luminata Crescendo Western HRP substrate (Merck Millipore). Quantification of chemiluminescence signals was performed using NIH ImageJ software.

\subsection{Immunocytochemistry}

Monolayer PDCL cultures were PFA-fixed and immunolabeled for native proteins using antibodies described in Supplementary Materials. Images were acquired in a sequential mode, using suitable filter cubes on a Leica DMI6000 microscope controlled by SimplePCI Software (Compix-Hamamatsu).

\subsection{Animal experimentation}

All animal experiments were conducted in accordance with the European Communities Council Directive for animal care and experimentation (Directive 2010/63/ UE), and following the guidelines of the animal facility in Orsay (France) approved by the Ethical Committee (France, CEEA 59) and the Direction of veterinary services (France, agreement D91-471-104). $1 \times 10^{6}$ dissociated cells were subcutaneously injected into the left flank of 8-weeks-old female nude mice. Tumor growth was monitored regularly and measured twice a week using a caliper as soon as tumors reach $25 \mathrm{~mm}^{3}$.

\subsection{Statistical analysis}

Patient survival was defined as the time between histological diagnosis and either death or the last follow-up. Differences between Kaplan-Meier survival curves were assessed using the log-rank test. For samples from the Pitié-Salpêtrière Hospital's cohort, gene expression levels were measured by qRT-PCR and compared between different molecular subgroups of patients using a one-way analysis of variance (ANOVA) and Mann-Whitney test (two-tailed) included in GraphPad Prism software. In the TCGA datasets, gene expression was compared between glioma subgroups with ANOVA and Tukey's comparison tests using R software. For cellular and molecular assays, experiments were performed in triplicates and repeated independently at least three times. Whenever relevant, Kruskal-Wallis or Mann-Whitney Wilcoxon tests were performed using R software. Differences were considered significant below $* p<0.05, * * p<0.01$ and $* * * p<0.001$ thresholds.
210 


\section{Results}

\subsection{A higher PAK3 expression in gliomas is associated with a longer patient survival}

We first analyzed PAK1-3 expressions in postnatal brain cell types by interrogating the database from the Barres group [22]. We found that $P A K l$ is highly expressed in neurons, oligodendrocyte lineage cells, microglia and to a lesser extent in astrocytes (Fig. 1a). PAK2 was expressed in all cell types and represented the main $P A K$ isoform in astrocytes and endothelial cells. PAK3 expression, overall lower than that of the two other $P A K$ genes, was restricted to neurons and cells of the oligodendroglial lineage. We next compared the expression levels of each $P A K$ isoform in tumors from the nervous system and other organs, by mining the Academic Medical Center (AMC) database (Fig. 1b) [23]. PAK1 was almost equally expressed in all tumor types, but at a slightly lower level in gliomas compared with other tumors, and less than in normal brain tissue. PAK2 was expressed at higher levels in all tumor types including gliomas, compared with normal brain tissue. Interestingly, $P A K 3$ levels were higher in gliomas and neuroblastomas compared with other cancers, with a heterogeneous distribution in gliomas. Interestingly, we found that $P A K 3$ displayed the same pattern of expression as $D C X$ in neural cell types and also in tumors $[19,22]$ (Fig. 1a,b; Supplementary Fig. S1). The relatively lower expression of $P A K 1$ and $P A K 3$ in gliomas compared to normal brain tissue is likely due to the high proportion of astrocyte-like cells, which express the lowest levels of $P A K 1$ and $P A K 3$.

We next investigated the correlation between PAKs expression and patient overall survival in a large cohort of glioma samples of diverse histological types and grades described by French and colleagues [24] (Fig. 1c). As we found that $P A K 2$ expression was not significantly correlated with survival $(p=0.084)$, we decided to focus on $P A K 1$ and $P A K 3$. Interestingly, high $P A K 1$ expression was found to be associated with a shorter survival and, conversely, high $P A K 3$ expression with a longer survival. For $P A K 3$, similar results were obtained from the Kawaguchi and REMBRANT glioma databases, underscoring a correlation between $P A K 3$ expression and patient survival (Supplementary Fig. S2). For PAK1 expression, similar results were obtained from most databases but not all, suggesting that the relationship between $P A K 1$ expression and tumor progression is weaker, or may depend on the different histological subtypes composing the cohort (data not shown). Using R2 software, we found that the PAK1 and $P A K 3$ expression levels did not correlate with each other $(\mathrm{r}=0.54)$, supporting an independent expression for each gene during cancer progression. Together, these data point to distinct roles for $P A K 1$ and $P A K 3$ in glioma development.

\subsection{PAK3 is highly expressed in IDH-mutant and $1 p / 19 q$-codeleted oligodendrogliomas}

To better understand the roles of PAK1 and PAK3 in the pathophysiology of gliomas, we next set out to investigate more precisely their expression levels in glioma subtypes, using qRT-PCR in 223 tumor samples from the OncoNeuroTek bank (Fig. 2 a-c). By doing so, we did not observe any significant difference in $P A K 1$ expression between grade II/III gliomas (lower grade gliomas: LGGs) and GBMs, whereas $P A K 3$ was significantly higher expressed in LGGs than in GBMs (Fig. 2a). More specifically, $P A K 3$ expression was higher in oligodendrogliomas compared with astrocytomas or oligoastrocytomas. In contrast, $P A K I$ expression was not significantly different among the LGG subtypes (Fig. 2b). In view of the new molecular classification for gliomas, we examined $P A K 1$ and $P A K 3$ expression according to the major alterations $I D H 1 / 2$ and $1 / 19 \mathrm{q}$ codeletion. Analysis of $P A K$ expression in $I D H-\mathrm{WT}$ and $I D H$-mutant LGGs revealed opposite results for each isoform, with a tendency towards increased $P A K 1$ expression in $I D H$-WT-LGGs and a significantly higher expression of $P A K 3$ in $I D H$-mutant LGGs (Fig. 2c). Moreover, in contrast to $P A K 1, P A K 3$ expression was significantly higher in gliomas harboring the $1 \mathrm{p} / 19 \mathrm{q}$ codeletion compared with noncodeleted tumors. To validate these results, we performed a meta-analysis of data from the TCGA including 582 human glioma samples (Fig. 2 d-f). For $P A K 3$, we detected a lower expression in GBMs than in LGGs, a higher expression in oligodendrogliomas than in other histological types, and a higher expression in $I D H$-mutant LGGs compared with non-mutant LGGs. In line with the PSH data, the TCGA analysis revealed a higher expression of $P A K 1$ in oligodendrogliomas and a lower expression in $I D H$-mutant LGGs. Together, these results indicate a higher $P A K 3$ expression in less aggressive gliomas.

\subsection{High PAK3 expression is a reliable marker for proneural subtypes of tumors and PDCLs}

GBMs can be classified in molecular subtypes according to their gene expression profiles. Interestingly, $P A K 3$ was found to be enriched in the proneural glioma subtype signature (Fig. S3) [6, 20]. We next examined this relationship using the transcriptional data obtained from tumors and matched cell lines described by Rosenberg [30]. We focused on a panel of selected genes that define the proneural signature, as established by Crisman [20]. We were able to confirm the higher expression of $P A K 3$ in samples classified as
282 283 
a

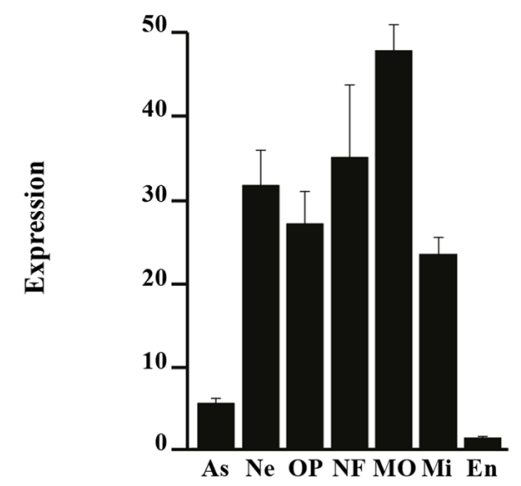

$P A K 2$

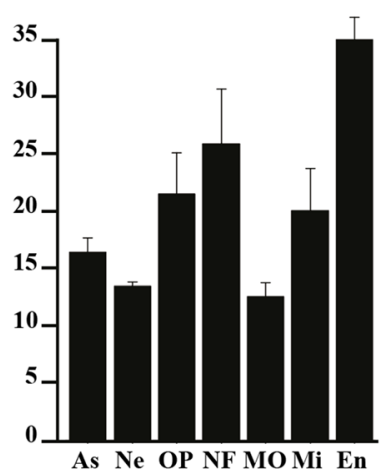

$P A K 3$

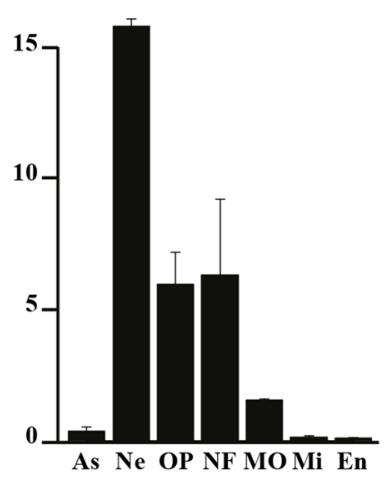

b

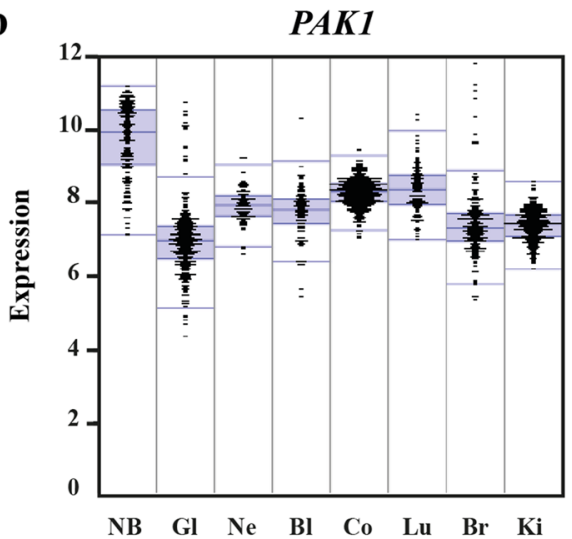

c

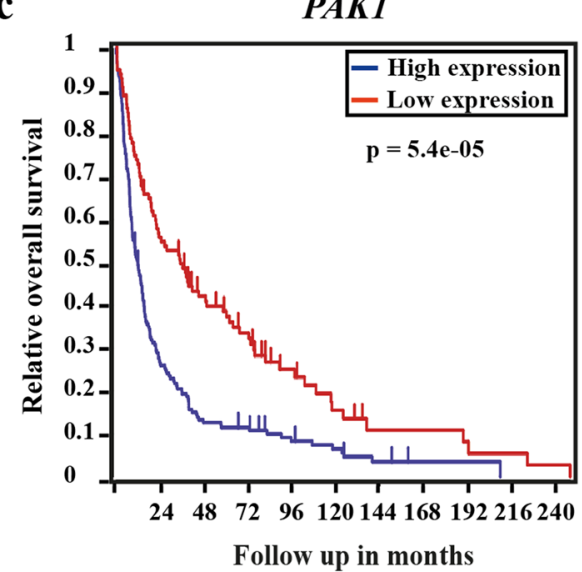

PAK2

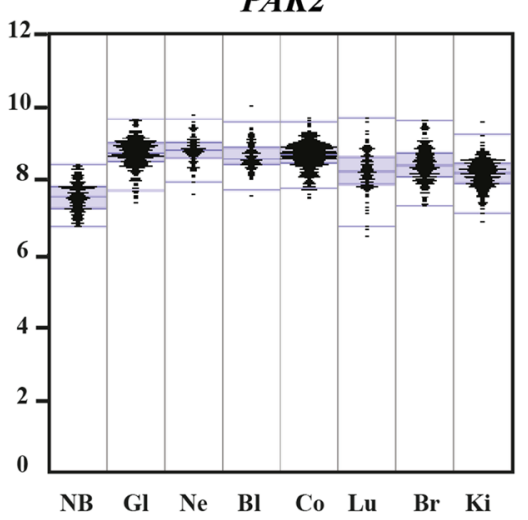

PAK2

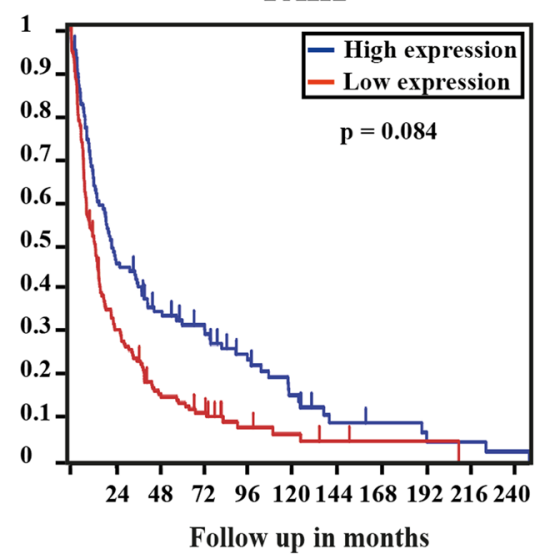

PAK3

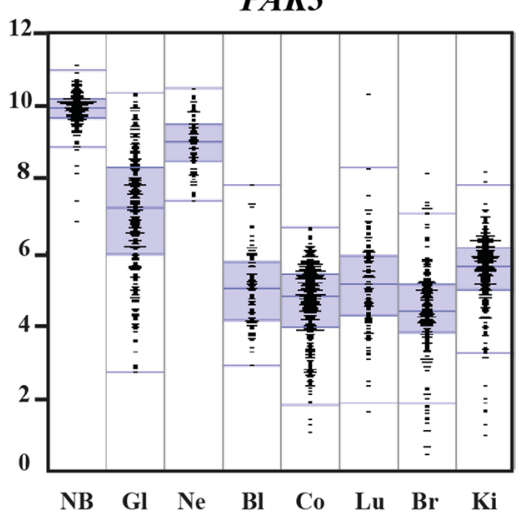

Fig. 1 PAK expression in CNS cellular population and correlation with survival of glioma patients. a, RNA-seq analysis of PAK expression in the postnatal mouse cerebral cortex shows specific patterns in different cell types. Data are mined from the transcriptomic database of Zhang et al. [22] and expressed in FPKM (Fragments Per Kilobase of exon per Million reads mapped) values. Astrocyte: As; neuron: Ne; oligodendrocyte progenitor cell: OP; newly formed oligodendrocyte: NF; myelinating oligodendrocyte: $\mathrm{MO}$; microglia: Mi; endothelial cell: En. b, $P A K 1$ is similarly expressed in all types of tumors, whereas $P A K 3$ is highly expressed in gliomas and neuroblastomas. Box plots show $\log 2$ gene expression levels in tumors from the Affymetrix u133p2 microarray, and from R2 platform analysis-
Academic Medical Center (AMC). The data are derived from the following cohorts: normal brain (NB, Berchtold, $\mathrm{n}=172$ ); glioma $(\mathrm{Gl}$, French, $\mathrm{n}=284)$; neuroblastoma (Ne, Versteeg, $\mathrm{n}=88$ ); bladder (B1, Riester, $\mathrm{n}=93$ ); colon (Co, Sieber Smith, $\mathrm{n}=355$ ); lung (Lu, Expo, $\mathrm{n}=114)$; breast $(\mathrm{Br}, \mathrm{Bos}, \mathrm{n}=204)$; kidney $(\mathrm{Ki}$, Expo, $\mathrm{n}=261)$. c, Contrary to $P A K 1$, high $P A K 3$ expression in gliomas is associated with a longer patient survival. Kaplan-Meier survival plot splitted according to $P A K$ expression level, AMC, French database. For $P A K 1$, high expression $\mathrm{n}=185$, low expression $\mathrm{n}=88$; for $P A K 2$, high expression $\mathrm{n}=113$, low expression $\mathrm{n}=160$; for $P A K 3$, high expression $\mathrm{n}=186$, low expression $\mathrm{n}=87$

\begin{tabular}{|l|l|l|l|l|}
\hline Journal : Large 13402 & Article No : 635 & Pages : 16 & MS Code : 635 & Dispatch : 6-9-2021 \\
\hline
\end{tabular}


qPCR

Pitié-Salpêtrière

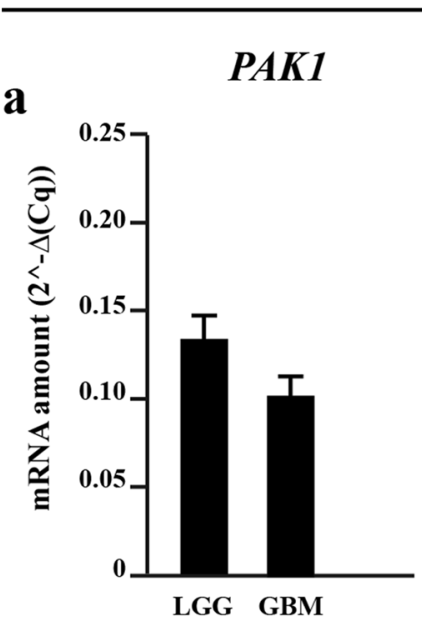

b

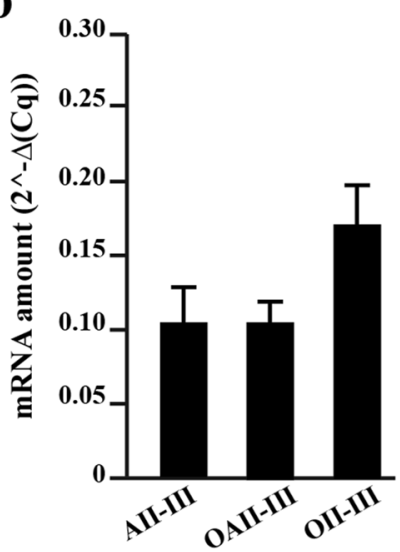

c

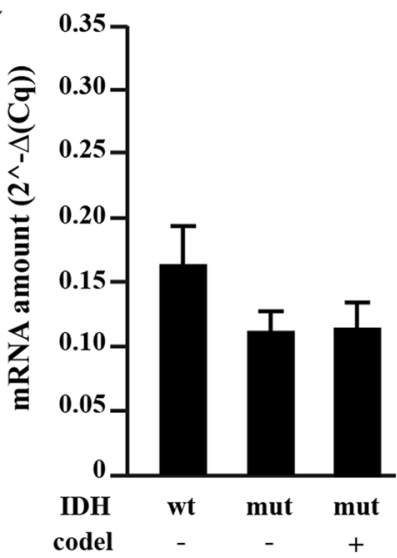

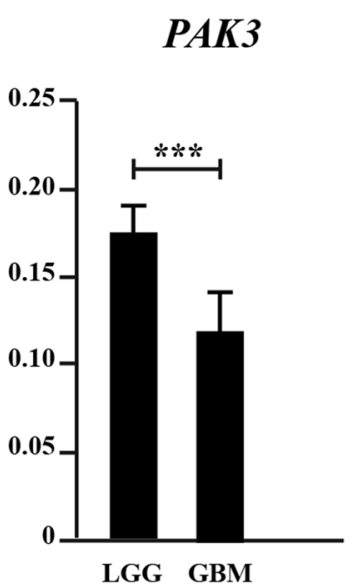
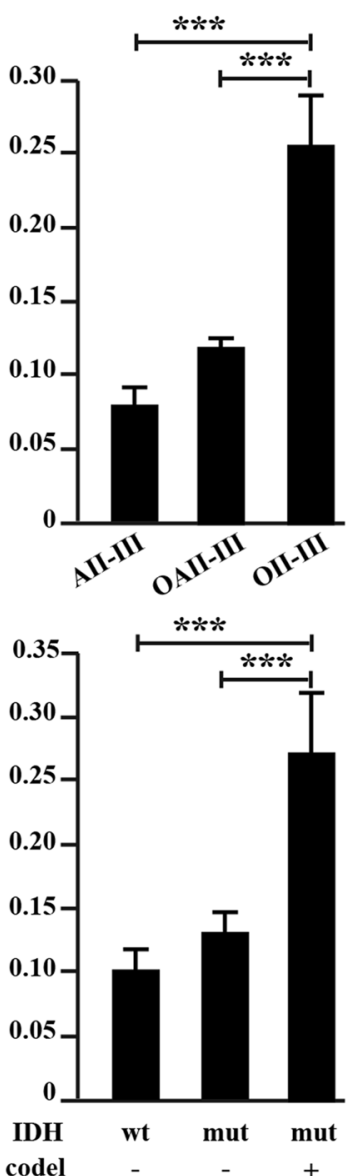

Fig. 2 PAK3 is highly expressed in IDH-mutant and 1p/19q-codeleted glioma subtypes. a-c: PAK1 and PAK3 gene expression levels were analyzed by qRT-PCR in glioma samples from the OncoNeuroTek bank. PAK1 and PAK3 mRNA expression levels are presented as $\Delta \Delta \mathrm{Cq}$; $\mathbf{a}$, in lower grade gliomas (LGGs, $\mathrm{n}=122$ ) versus glioblastomas (GBMs, $n=101)$; $\mathbf{b}$, in the various histological classes of LGG (A: astrocytoma, $n=15$; O: oligodendroglioma, $n=54$; OA: oligoastrocytoma, $\mathrm{n}=53$ ) and including II and III tumor grades; c, accord-
RNA seq

TCGA database

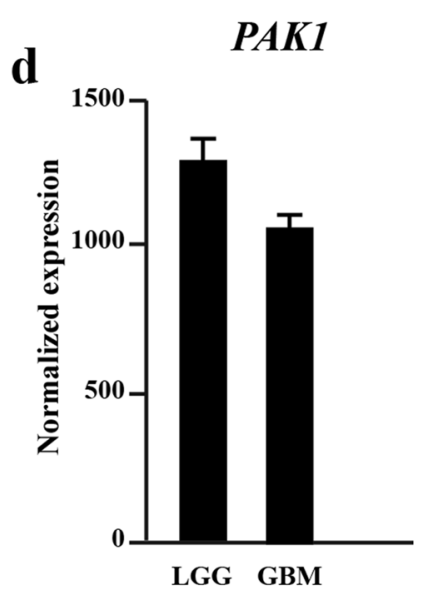

$P A K 3$
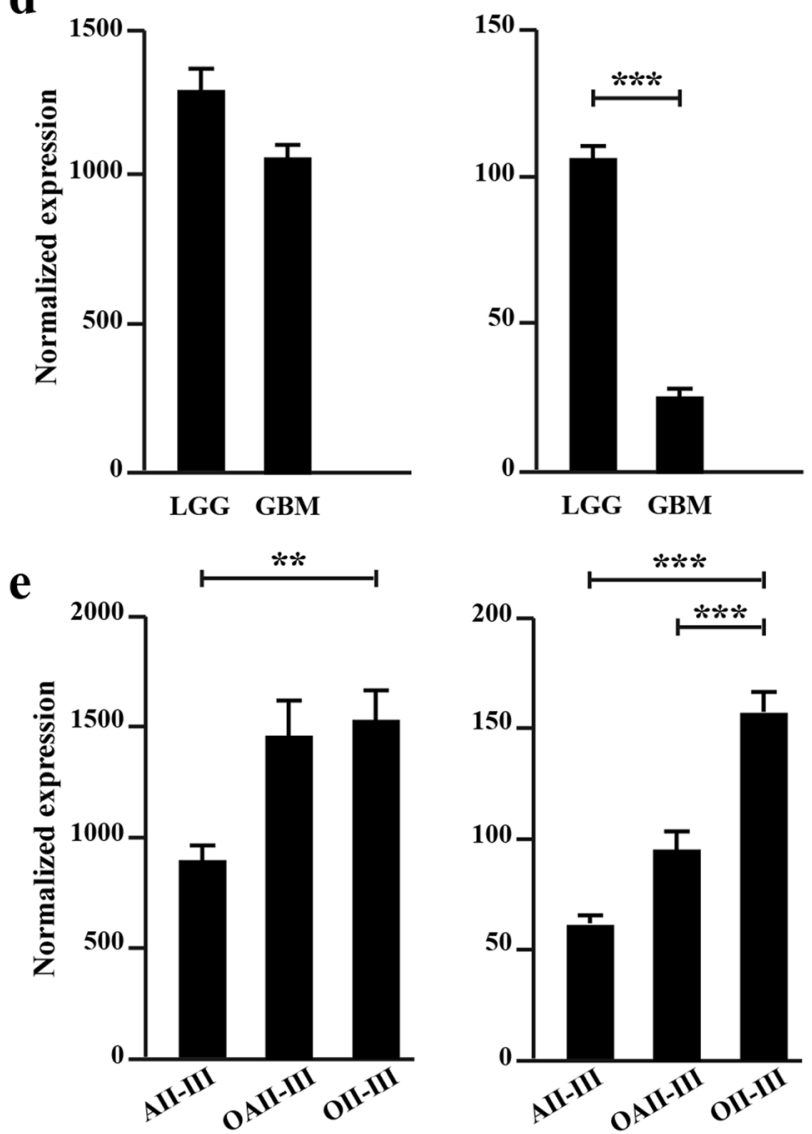

f
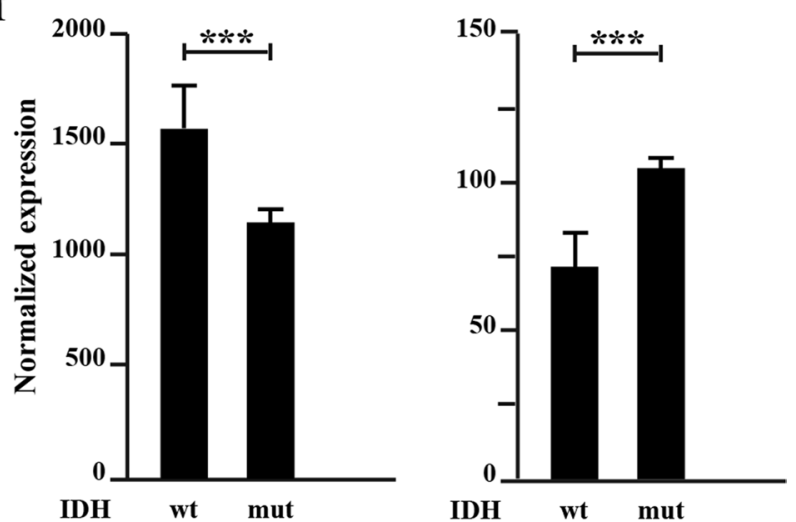

ing to IDH status and to $1 \mathrm{p} / 19 \mathrm{q}$-codeletion (IDH wild type: WT, $\mathrm{n}=28$; IDH mutant: mut; no codeletion $1 \mathrm{p} / 19 \mathrm{q}:-, \mathrm{n}=34$; codeletion 1p/19q:,$+ \mathrm{n}=47)$. d-f, $P A K 1$ and $P A K 3$ gene expression analyzed from the TCGA database; $\mathbf{d}$, in lower grade gliomas (LGGs, $\mathrm{n}=417$ ) versus glioblastomas (GBMs, $n=165)$; $\mathrm{e}$, in the various histological classes of LGG (A, n=149; O, n=159; OA, $n=109$ ) and including II and III tumor grades; f, according to IDH status (wild type: WT, $\mathrm{n}=98$; mutant: mut, $\mathrm{n}=434$ ) 
a

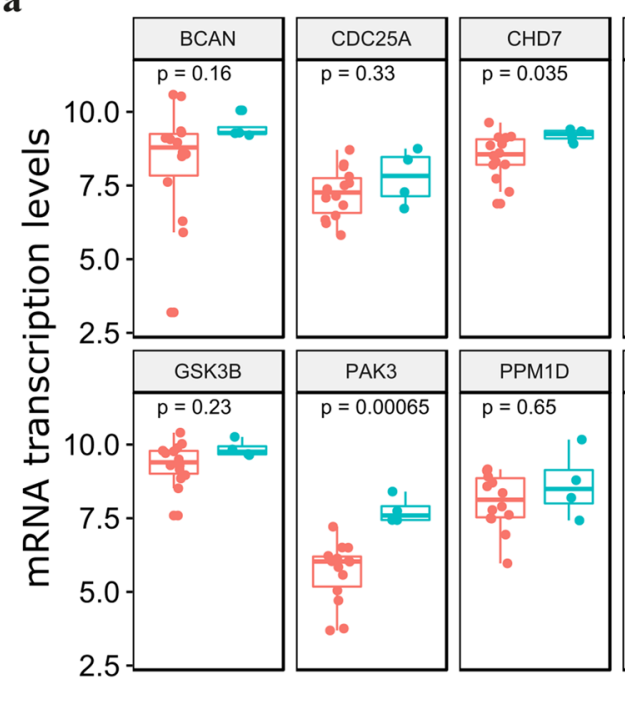

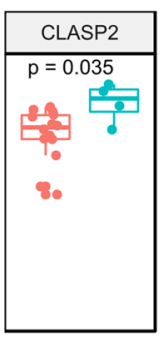

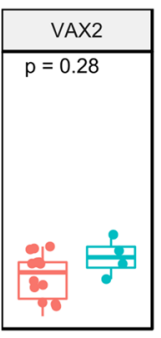

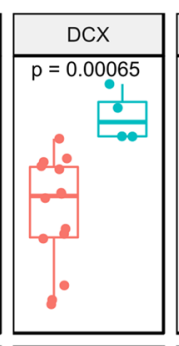

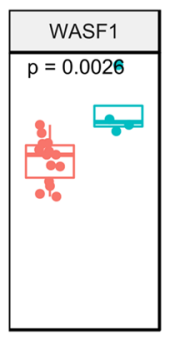

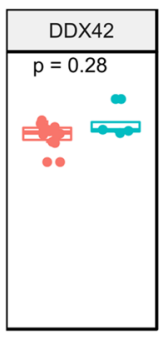

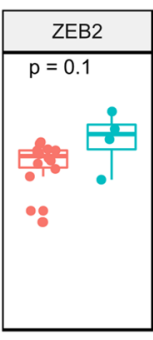

Other

Proneural

b

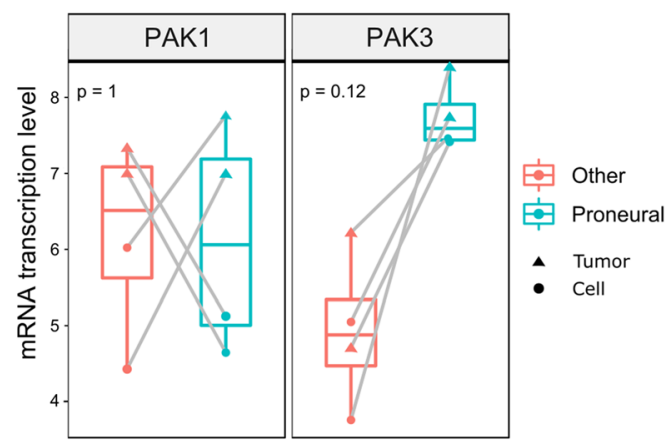

c

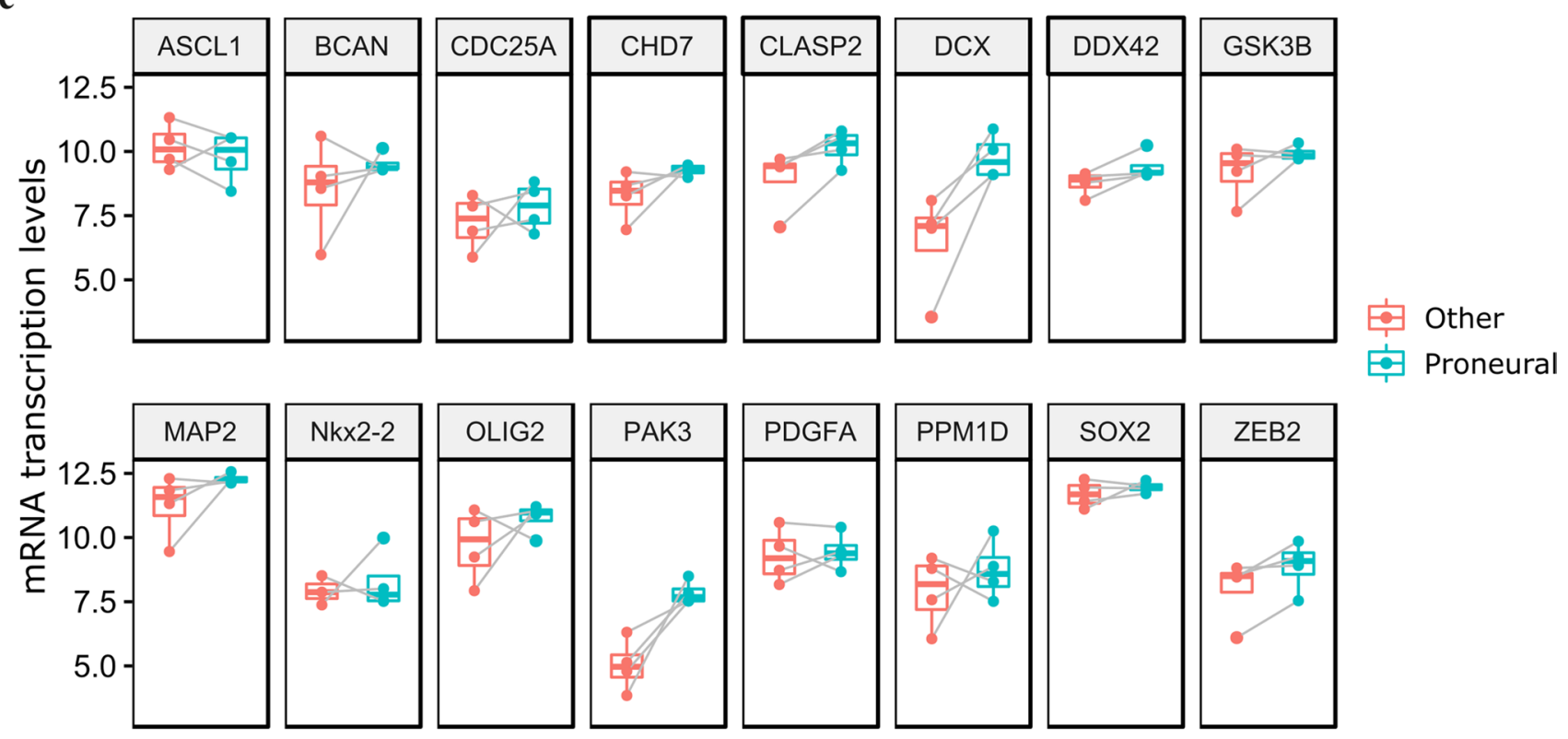

Fig. 3 High PAK3 expression in primary tumors and their PDCLs correlates with proneural subtypes. Data were extracted from a transcriptome analysis performed by Rosenberg et al. [30]. a, Expression of Crisman proneural signature genes in proneural or non proneural subtypes (16 samples corresponding to 8 tumors and 8 PDCLs); b, PAK1 and PAK3 expression levels in tumors and their corresponding PDCLs. c, expression levels of proneural signature genes in paired tumors and corresponding PDCLs

\begin{tabular}{|l|l|l|l|l|}
\hline Journal : Large 13402 & Article No : $\mathbf{6 3 5}$ & Pages : 16 & MS Code : 635 & Dispatch : 6-9-2021 \\
\hline
\end{tabular}


proneural, regardless of sample type (tumors or PDCLs) (Fig. 3a). PDCLs have been developed both for analysing the biology of human tumors and as preclinical models for screening potential therapeutic agents. The analysis of phenotype transition may be relevant with regard to tumor evolution towards a more aggressive mesenchymal phenotype [3]. Although in most cases PDCLs maintain the molecular subgroup signature of the parental tumor, some PDCLs acquire characteristics of other phenotypic groups [30]. We asked whether the $P A K 3$ expression level may represent a marker for the proneural subtype during tumor/PDCL phenotypic transition. Previously, GBM subtypes were found to be maintained in 5/9 of the paired tumors/PDCLs, whereas 4/9 cases exhibited subtype changes [30]. Interestingly, when we analysed these cases, we consistently observed higher $P A K 3$ levels in the proneural samples, regardless of the kind of change and tissue (Fig. 3b,c). Note that PAKI expression was always lower in PDCLs compared to tumors, without subtype correlation (Fig. 3b). In case the subtype changes during cell line establishment, increased expression of PAK3 was observed in PDCLs which acquire this proneural subtype and, conversely, its expression was found to decrease when the PDCLs lost this proneural subtype. Expression comparisons of the other proneural genes, such as ASCL1, DCX, MAP2, NKX2.2, OLIG2, PDGFRA and $S O X 2$ selected from the Vehraak list, and BCAN, CDC25A, CHD7, CLAPS2, DCX, DDX42, GSK3, PPM1D, WASF1 and $Z E B 2$ selected from the shortlist defined by Crisman, we found that tumors and cell samples attributed to the proneural subtype compared to other subtypes clearly indicated that among the genes of the proneural signature, only $P A K 3$ and $D C X$ displayed a higher expression in proneural tumors and PDCLs (Fig. 3c). Thus, these data indicate that $P A K 3$ serves as a reliable marker for the proneural characterization of tumors and PDCLs.

\subsection{High PAK3 expression negatively relates to PDCL proliferation}

In order to better characterize the association between PAK3 expression and glioma cell biology, we analyzed PAK3 expression in 3 PDCL cultures named 3731a, 3731b and 4371 [27] that are growing as spheroids in EGF-FGF defined medium (Fig. 4a). These PDCLs harbor EGFR amplifications and 3731a and b, derived from the same initial 3731 cell line, express the mutated oncogene EGFRvIII [27]. We found that the two 3731 PDCLs displayed a transcriptomic profil with a more prounnonced mesenchymal/classical signature compared to the $4371 \mathrm{PDCL}$, which displays a proneural expression phenotype, as established by qRT-PCR analysis of genes representative of the four Verhaak GBM subtypes (heatmap: Fig. 4b, Fig. S4).
In cultured spheroids, $P A K 3$ expression was significantly higher in 4371 cells compared to the two other cell lines, as measured by qRT-PCR (Fig. 4c). Cell growth analysis showed that $3731 \mathrm{a}$ and $3731 \mathrm{~b}$ exhibit faster proliferation rates than 4371, with fold increases after one week, of 16 , 17 and 12, respectively (Fig. 4d). Accordingly, the expression levels of $C C N D 1$ and of $C D K N 1 B$ were the lowest and highest, respectively, in the slow proliferative 4371 cells compared with the $3731 \mathrm{a} / \mathrm{b}$ cells (Fig. 4e). We conclude that $P A K 3$ expression is higher in slower growing PDCLs.

\subsection{High PAK3 expression positively associates with neuronal differentiation}

We next analyzed $P A K 3$ expression during PDCL differentiation induced after growth factor withdrawal in monolayer cultures as previously described [31]. In these conditions, no cell death was observed in the three PDCL cultures (data not shown). PAK3 expression was analyzed after 3 days ( $\mathrm{t} 3$ ) and 8 days ( $\mathrm{t} 8)$, compared with proliferative conditions ( $\mathrm{t} 0$ ). We found that in the two 3731 PDCL cultures PAK3 expression was strongly induced at both the mRNA and protein levels, in contrast to that in 4371 cells (Fig. 5a-b, Fig. S5a). In proliferative conditions ( $\mathrm{t} 0$ ), the proportion of $\mathrm{KI} 67^{+}$cycling cells varied between PDCL cultures, from 90\% (3731b) to $60 \%$ (4371) (Fig. 5c and S5b, first column), in accordance with the rates observed in sphere cultures (Fig. 4b). After growth factor withdrawal, the proportion of $\mathrm{KI} 7^{+}$cells was largely reduced for 3731a and 4371 (t8, 22\%), and to a lesser extent for $3731 \mathrm{~b}$, which remained highly proliferative ( $\mathrm{t} 8$, $65 \%$ ). Accordingly, $p 27-K I P 1$ expression increased after induction of growth arrest in the three PDCL lines (Fig. 5d). We next analyzed GFAP and DCX expression in monolayer cultures by immunolabeling and mRNA and protein quantification (Fig. S5c, Fig. 5e-f). For 3731b cells, growth factor withdrawal had little effect on the expression of the cell differentiation markers $D C X$ and GFAP. In contrast, we found that the 3731a and 4371 cell lines displayed a reduced proliferation with an increased expression of both GFAP and DCX.

Next, PDCL cultures were exposed to bone morphogenetic proteins 4 (BMP4) and all-trans retinoic acid (ATRA) in order to induce astroglial and neuronal differentiation, respectively $[32,33]$. We found that BMP4 or ATRA treatment did not modify the proportion of proliferating cells compared to growth factor withdrawal alone (Fig. S6a). Cell lineage differentiation was assessed using qRT-PCR expression analysis of DCX GFAP, OLIG2, NG2, PDGFRa, S100beta and TUBB3 (Fig. 5, Fig. S6b). BMP4 treatment had a relatively little effect on $P A K 3$ expression in the three PDCL cultures, except for a strong GFAP transcriptional activation in $3731 \mathrm{~b}$ cells and moderate in 3731a cells, suggesting astroglial differentiation 
$\mathbf{a}$
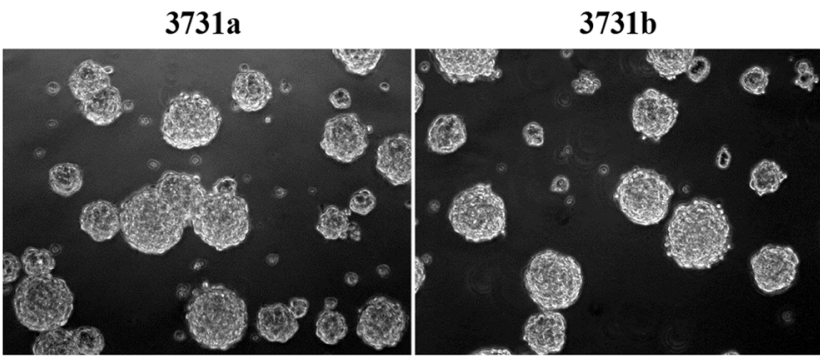

4371

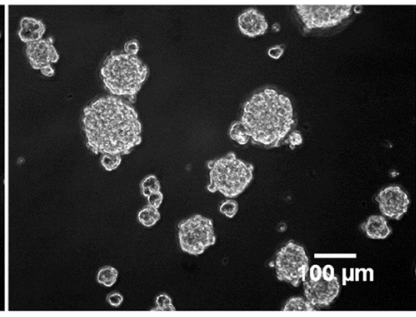

b

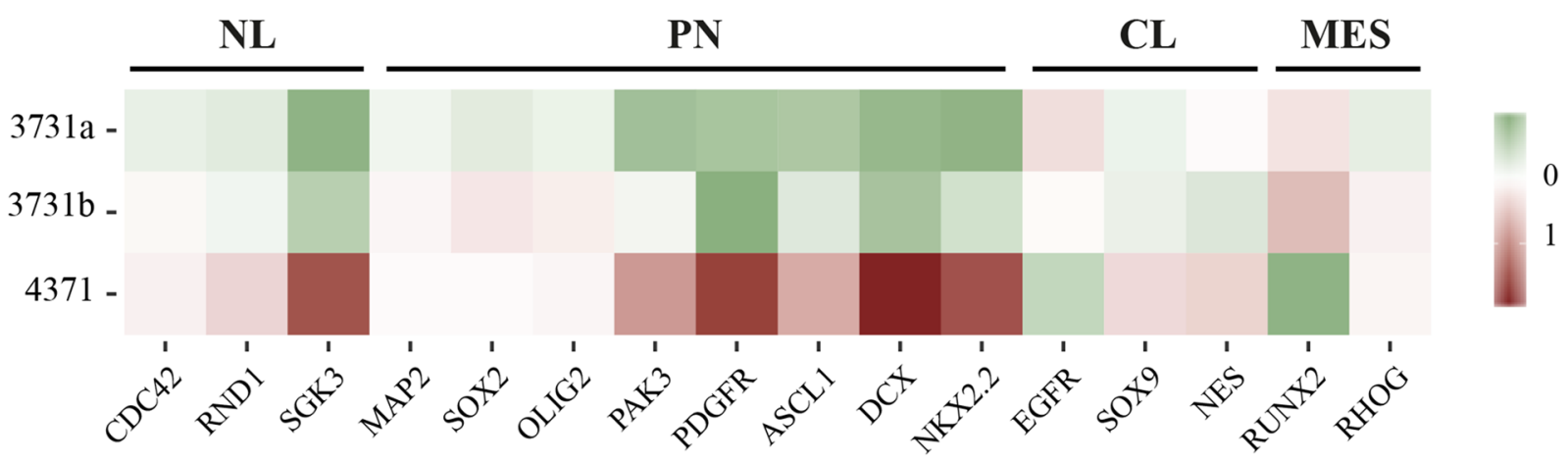

c

$\square 3731$ a $\square 3731$ b $\square 4371$

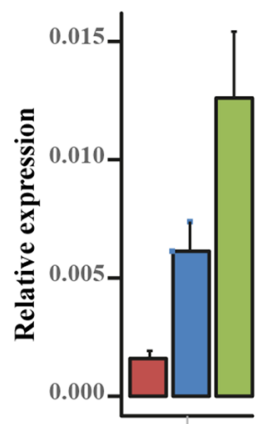

PAK3 d

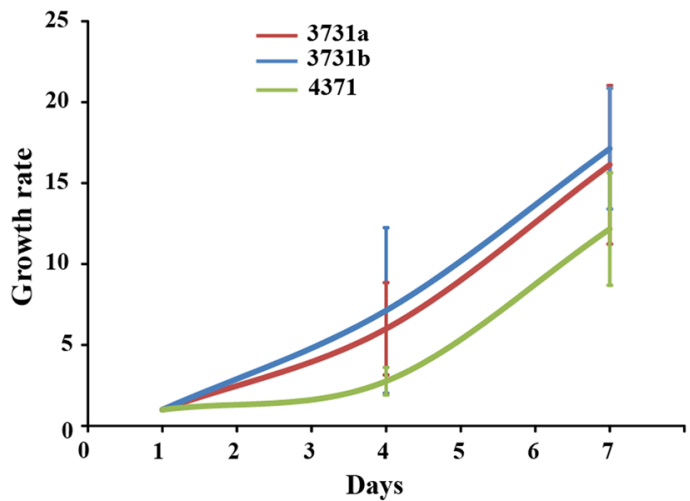

$\mathbf{e}$

$\square 3731$ a $\square 3731$ b $\square 4371$

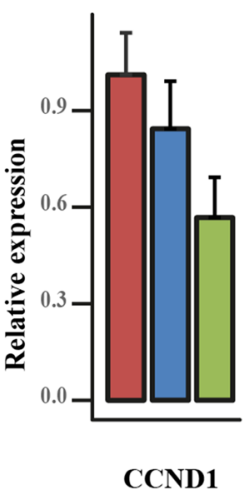

Fig. 4 High PAK3 expression negatively correlates with PDCL proliferation. a, Representative images showing spheroids grown for 7 days. b, Heat map representation of subtype signature gene expression in 3731a, 3731b and 4371 cells. Expression is shown relatively to the mean (red: higher expression level; green: lower expression; white for the mean). Genes are organized according to gene expression signatures: Mesenchymal (MES), Classical (CL), Proneural
(Fig. 5g). ATRA treatment induced a strong transcriptional activation of $P A K 3$ in 4371 cells and, to a lesser extent, in 3731 a cells, associated with expression of the neuronal markers $D C X$ (Fig. 5h) or TUBB3 (Fig. S6b). In summary, we found that growth factor withdrawal induced an increase in PAK3 expression associated with GFAP and $D C X$ expression in mesenchymal/classical 3731 cell
(PN) and Neural (NL). c, qRT-PCR analysis of PAK3 expression in PDCL spheres. Expression levels are presented as $\Delta \Delta \mathrm{Cq}$, relatively to human fetal brain as external reference. d, Fold increase in cell number over time, day1 to 7 (d1, d4 d7). e, qRT-PCR analysis of cell cycle genes. Expression levels are presented as $\Delta \Delta \mathrm{Cq}$, relatively to human fetal brain as external reference. For all analyses, data represent at least three independent experiments

lines, whereas ATRA treatment induced $P A K 3$ and $D C X$ up-regulation mainly in the proneural PDCLs (Fig. 5i). In contrast, BPM4 induced glial differentiation in mesenchymal cell lines without affecting $P A K 3$ expression. This highlights a link between $P A K 3$ expression and neuronal differentiation.

\begin{tabular}{|l|l|l|l|l|}
\hline Journal : Large 13402 & Article No: 635 & Pages : 16 & MS Code : 635 & Dispatch : 6-9-2021 \\
\hline
\end{tabular}


Fig. 5 High PAK3 expression is positively correlated to neuronal differentiation. a-f: PDCLs were grown as monolayers in proliferative medium ( $\mathrm{t} 0$ ) or without growth factors in $0.5 \%$ FCS for $3(\mathrm{t} 3)$ or $8(\mathrm{t} 8)$ days. a, qRT-PCR analysis of $P A K 3$ expression during the time course after growth factor withdrawal, expressed relatively to that in normal human fetal brain as external reference. $\mathbf{b}$, Western blot analysis of PAK3 protein expression with actin as loading control. c, Percentage of Ki67-positive cells relative to DAPI staining. d, qRT-PCR analysis of p27 expression relative to that in normal human fetal brain as external control. e, qRT-PCR analysis of $D C X$ and GFAP expression relative to that in normal human fetal brain as external reference. f, Western blot analysis of DCX and GFAP expression with actin as control, in PDCLs over time. g-i: Cells were grown as monolayers in proliferative medium and then without growth factors in the absence of FBS (0\%), or in the presence of BMP4, DMSO or all trans retinoic acid (ATRA) for 3 (t3) or 8 (t8) days. $\mathbf{g}, \mathbf{h}$, qRT-PCR analysis of gene expression at $\mathrm{t} 3$ and t8, expressed relative to the $t 0$ value of each PDCL culture, in the absence $(0 \%)$ or presence of BMP4 (g), and in the presence of DMSO as a control or ATRA (h). i, Diagram showing the variations in gene expression levels after growth factor withdrawal, BMP4 or ATRA treatment. For all these qRT-PCR (expressed as $\Delta \Delta \mathrm{Cq}$ ) or Western blot analyses, data represent at least three independent experiments

\section{Growth factor withdrawal}

a

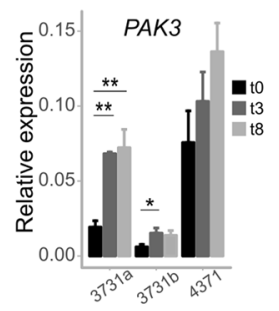

c

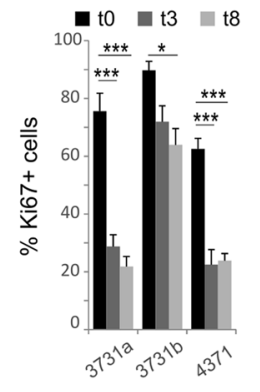

e

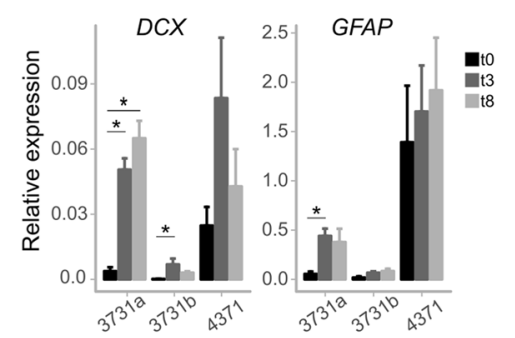

g

Bone Morphogenetic Protein

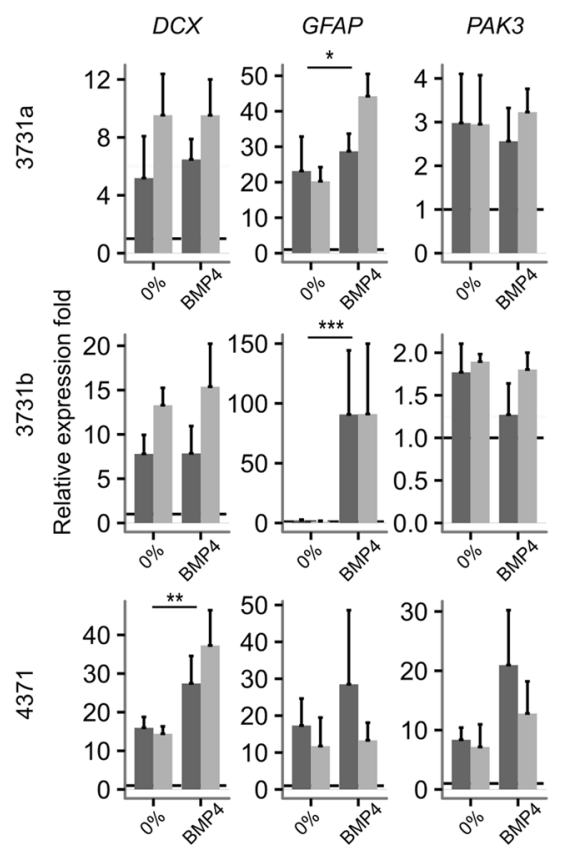

i

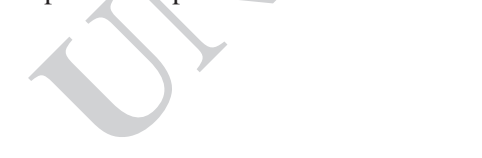

$\frac{1}{60-\frac{*}{1}}$ b

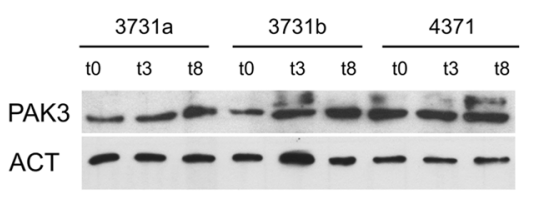

d

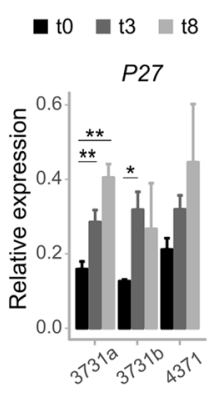

f

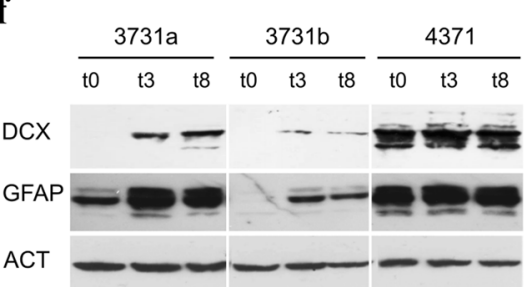

h

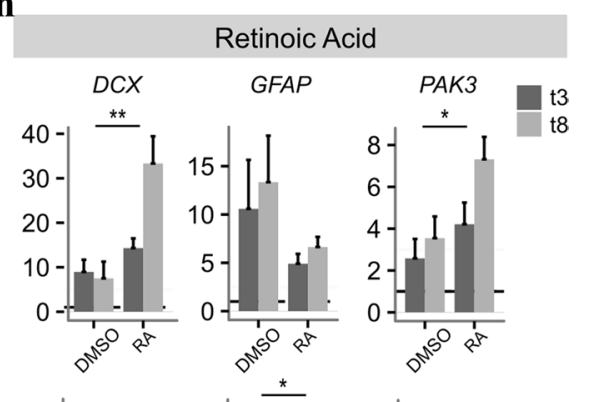

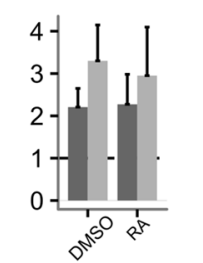
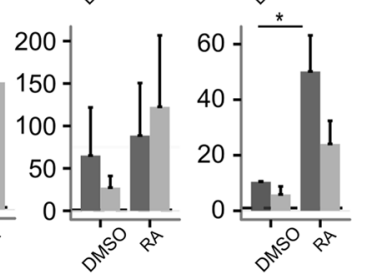

BMP4

DCX GFAP PAK3

Retinoic acid

DCX GFAP PAK3

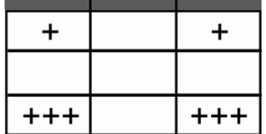


$\mathbf{a}$

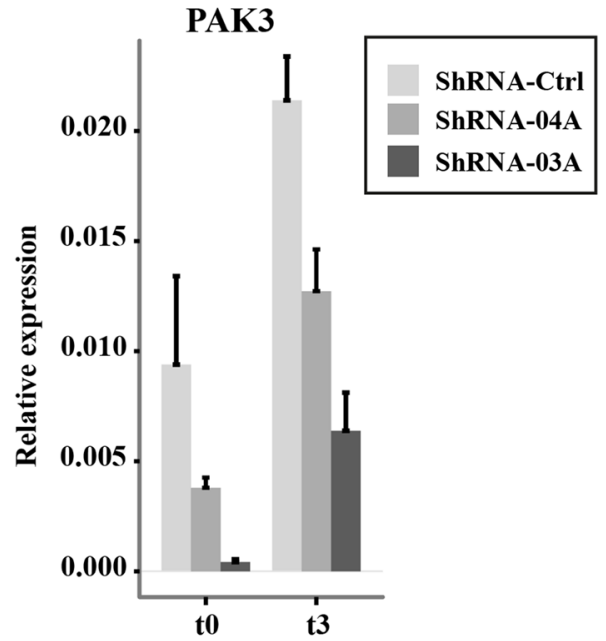

d

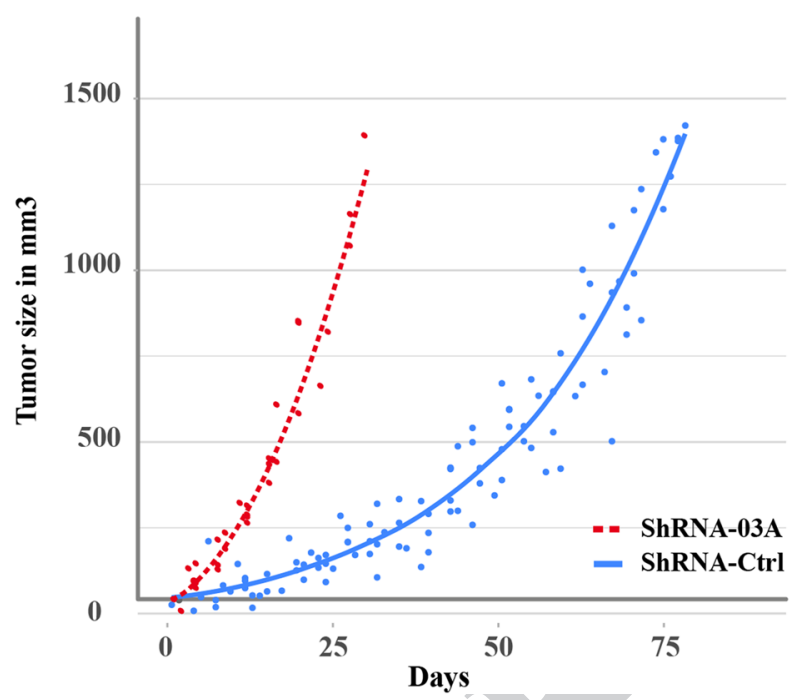

Fig. 6 ShRNA-mediated inhibition of PAK3 expression modifies glioma cell proliferation, differentiation and tumor growth. a-c: 3731a PDCLs stably transduced with Control-shRNA (Ctrl) or PAK3shRNA $(03 \mathrm{~A}, 04 \mathrm{~A})$ lentiviral vectors were grown as monolayers in proliferative medium ( $\mathrm{t} 0$ ) or three days after growth factor removal and in $0.5 \%$ FCS (t3). a, qRT-PCR analysis of PAK3 expression relative to that in normal human fetal brain $(n=3)$. $\mathbf{b}$, Percentage of Ki67 ${ }^{-}$positive cells. c, qRT-PCR analysis of GFAP and $D C X$ expression relatively to that in normal human fetal brain $(n=3)$. d, e: Mice b

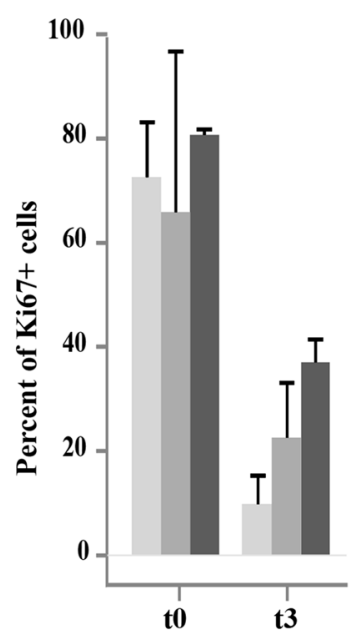

c
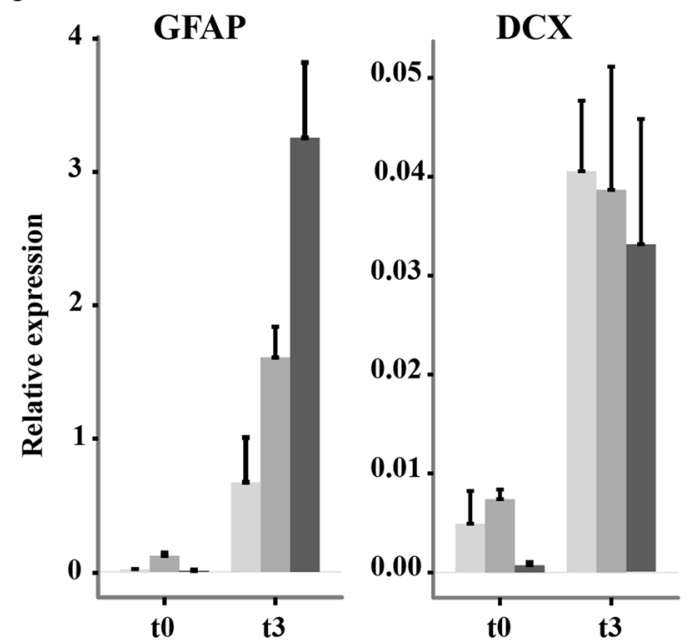

e

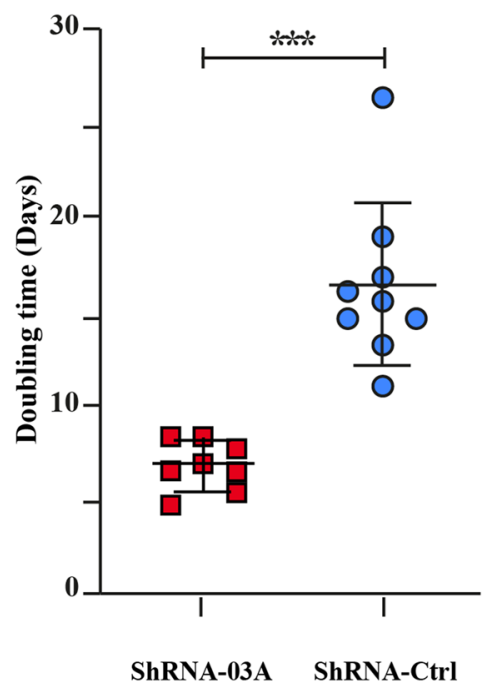

were subcutaneously injected with $P A K 3$-shRNA-03A-transduced 3731a cells $(03 \mathrm{~A})(\mathrm{n}=9)$ or the Control-shRNA-transduced 3731a cells as control $(\mathrm{Ctrl})(\mathrm{n}=8)$. d, Tumor growth over time analyzed after tumors reached $25 \mathrm{~mm}^{3}$; mean curves were obtained by LOESS method. e, Mean doubling time \pm SD of Control and Sh03A tumor growth. The doubling time parameter was extracted after exponential growth curve modeling. Each individual data point represents one mouse

inhibition was obtained in 3731a cells with Sh-03A, and to a lesser extent with Sh-04A, in proliferative conditions (t0) and after growth factor withdrawal (t3), compared to the Control-shRNA (Fig. 6a). In proliferative conditions (t0), inhibition of $P A K 3$ expression by the two shRNAs had $\quad 454$ no effect on cell proliferation, as revealed by Ki67 analysis $\quad 455$ (Fig. 6b). However, after three days without growth fac- 456 tors (t3), the proportion of Ki67-positive cells increased in 457 the PAK3-knock down compared to control cells. We next 458

\begin{tabular}{|l|l|l|l|l|}
\hline Journal : Large 13402 & Article No : 635 & Pages : 16 & MS Code : 635 & Dispatch : 6-9-2021 \\
\hline
\end{tabular}


evaluated GFAP and DCX expression in PAK3-shRNA3731a cells, in proliferative conditions (t0) and after growth factor withdrawal (t3), compared to Control-shRNA expressing cells. Inhibition of $P A K 3$ expression had no effect on GFAP expression in proliferative medium ( $\mathrm{t} 0$ ) whereas the GFAP level increased notably after growth factor withdrawal (t3) (Fig. 6c). Furthermore, no significative effect was observed on $D C X$ expression under the same experimental conditions. These results indicate that inhibition of $P A K 3$ expression in GBM cells induces astroglial differentiation.

Finally, to analyze the effect of PAK3 inhibition on glioma cell tumorigenicity in vivo, we decided to choose the 3731a PDCL that forms subcutaneous tumors in mice, whereas 4371 does not (data not shown). Sh-03A or ControlshRNA transduced 3731 a cells were injected subcutaneously in nude mice. Monitoring of tumor sizes clearly indicated that tumors grew faster in the Sh-03A-cells injected mice compared to the Control-shRNA injected mice (Fig. 6d). Doubling times were extracted from the exponential growth curves. Compared to the control $(15.38 \pm 3.23$ days $)$, the doubling time for the Sh-03A-cells injected mice was shorter $(6.43 \pm 1.64$ days), indicating an increase in tumor growth (Fig. 6e). PAK3 expression levels were found to be lower in tumors isolated from the four mice injected with $P A K 3$ shRNA transduced cells, compared with tumors isolated from mice injected with Control-shRNA-cells, indicating that Sh-mediated $P A K 3$ silencing is maintained over time (Fig. S7). This allows us to confirm the correlation between $P A K 3$ expression in GBM cells and tumour growth. However, we did not observe any increase in the expression of glial markers, such as GFAP or SOX9, in tumors derived from cells transduced with $P A K 3$-shRNA, compared to Control-shRNA tumors (Fig. S7). These results strongly suggest that inhibition of $P A K 3$ expression in GBM cells impacts their differentiation fate towards an astroglial phenotype in vitro and promotes their tumor growth in vivo.

\section{Discussion}

We here report correlations between PAK expression in gliomas and patient survival that are specific of each isoform. We found that $P A K I$ expression in tumors is negatively correlated to patient survival, suggesting that $P A K 1$ may favor glioma tumor growth, in accordance with its reported oncogenic functions in other cancers $[17,18]$. We found that the $P A K 2$ expression level is not related to survival but that, in contrast, a high $P A K 3$ expression is associated with a better survival. These results clearly indicate distinct and unique roles for each $P A K$ isoform in the pathophysiology of gliomas. Interestingly, we found a higher $P A K 3$ expression level in $1 \mathrm{p} / 19 \mathrm{q}$-codeleted tumors, which are tumors with oligodendrocyte characteristics associated with a better prognosis, raising the question whether $P A K 3$ acts as tumor suppressor or simply as a marker of the differentiated status of these tumors. Indeed, during brain development $P A K 3$ possesses differentiating functions, being involved in neuronal cell specification, neuroblasts differentiation and oligodendrocyte differentiation [13-16]. These functions may act during tumor development and favor neuronal differentiation of glioma cells.

To address this question, we performed a comparative study on several PDCLs. The different cell cultures used displayed distinct characteristics, particularly regarding $P A K 3$ expression. The two 3731 PDCL clones grew fast, exhibited classical/mesenchymal transcriptomic signatures, formed tumors after subcutaneous engraftment and displayed a low PAK3 expression, compared to the 4371 PDCL. Following growth factor withdrawal or ATRA treatment the 3731a subclone differentiated towards an immature neuronal state associated with an increase in $P A K 3$ expression, whereas the $3731 \mathrm{~b}$ subclone showed upregulated GFAP expression upon BMP4 treatment, without any change in PAK3 expression. This suggests that these cells undergo an astroglial differentiation or acquire stem cell-like properties, independently of PAK3 expression. The 4371 PDCL culture possesses opposite characteristics: it grew more slowly, expressed a more proneural transcriptomic profile and did not form tumors after xenografting. Interestingly, it expressed a relatiyely higher level of $P A K 3$ and neuroglial differentiation markers. Growth factor withdrawal and BMP4 treatment induced only a small increase in neuroglial differentiation, whereas treatment with ATRA induced a strong increase in the expression of neuronal markers such as $D C X$, as well as $P A K 3$ expression. These results are in agreement with distinct differentiation characteristics of PDCLs upon different differentiation-inducing regimens [34]. However, our data clearly show that an increased $P A K 3$ expression was associated with neuronal differentiation in two PDCL cultures, suggesting that $P A K 3$ favors neuronal differentiation and decreased proliferation of glioma cells, as $P A K 3$ does during normal brain development.

We found that $P A K 3$ expression knockdown resulted in an increase in PDCL proliferation associated with an increase in GFAP expression in vitro and an increase in tumor growth rate in engrafted mice. These results strongly suggest that PAK3 can promote neuronal differentiation and/or inhibit astroglial differentiation, leading to slow tumor growth. In our setting, we did not observe any increase in astrocytic markers in PAK3-shRNA tumors. Among several possible explanations, the most likely is that the analysis of the cellular phenotype was carried out relatively late, i.e., mice were euthanized after having reached a tumor stage at which cellular regulations and phenotypes are radically modified. Some brain-specific factors present in culture media of PDCLs, but absent in the xenograft environment, could be 
necessary for inducing an astrocytic phenotype shift. Astroglial cell fate inhibition may be due to a direct inhibition of astrocyte differentiation or an indirect effect of the activation of neuronal differentiation triggered at the expense of astrocytic differentiation, as observed earlier during Xenopus embryogenesis [13].

The PAK3 gene belongs to a group of genes characteristic of a proneural signature. This was established in the princeps study of Verhaak and collaborators and also in the shortlist of 48 genes for this same subtype, established by different algorithms in the study of Crisman and colleagues $[6,20]$. More recently, scRNA-seq allowed a delineation of the transcriptomes of single glioblastoma cells, their intratumoral heterogeneity and their phenotypic plasticity. The main identified subgroups of cells are characteristic of neuronal and glial lineages or their progenitors. Interestingly, the $P A K 3$ gene belongs to the top 30 genes that define neural progenitor cells (NPCs) specifically involved in the neuronal lineage (NPC2) [35]. Here, we confirmed a key status of the $P A K 3$ gene for a proneuronal signature in tumors as well as in PDCLs. This underlines its weight as a subgroup indicator, but at the same time raises the question of its role in the biology of these tumors. In particular, it remains to be determined how PAK3 could have opposite roles to those of PAK1 in the biology of gliomas. A first possibility may be that PAK3 has its own substrates. Currently, most PAK substrates involved in cancer have been identified for PAK1, but these have not been validated for other group I kinases $[19,36]$. A hypothesis may be that PAK3 uses one or more yet unknown substrates that are not phosphorylated by PAK1 and are involved in the inhibition of cell division, or in the initiation of neuronal differentiation. Another hypothesis may be that PAK3 belongs to a signaling pathway involved in a negative regulation of tumor growth. We have previously shown that PAK3 signaling differs from that of PAK1 at several points, PAK3 being activated by the Rho GTPase Cdc42 and preferentially binding to the Nck2/Grb4 adapter $[37,38]$. These pathways are known to act in tumor proliferation, differentiation and progression, but their role in the biology of gliomas is still poorly understood. Another possibility may be that PAK3 can act on cell proliferation by inhibiting PAK1. Indeed, the PAK kinases have been reported to form dimers that allow their trans-inhibition $[39,40]$. However, we have previously shown that the PAK3 protein prefers to form heterodimers with PAK1 rather than homodimers, leading to inhibition of PAK1 kinase activity [29]. Thus, a transcriptional increase of $P A K 3$ in gliomas could lead to a decrease in PAK1 activity.

Although $P A K 1$ and $P A K 2$ are well characterized oncogenes, our data strongly suggest that $P A K 3$ acts as a tumor suppressor gene [17, 36, 41]. PAK genes are rarely mutated in cancer and the analysis of mutation databases does not alow to discriminate mutational patterns between PAKI and PAK3 (CBioPortal) [42]. On the other hand, PAK1/2 genes are often overexpressed in cancer, as recently reported for breast cancer, in contrast to $P A K 3$ [43]. $P A K 1$ is mainly involved in cancer development through functional activation, due to transcriptional or post-translational processes. Here, our transcriptomic analysis showed a strong correlation between PAK3 expression and patient survival, and the functional experimens we performed indicate that $P A K 3$ may indeed be considered as a tumor suppressor. One consequence of our results relates to possible therapeutic approaches. They stress the need to analyze, in different tumor types, the expression and activation of oncogenic PAK kinases such as PAK1 or PAK2, but also that of PAK3. Indeed, the use of non-selective PAK kinase inhibitors could have deleterious effects by inhibiting the PAK3 tumor suppressor gene. To date, there are no specific PAK inhibitors that do not inhibit PAK3 [44]. Our data do suggest, however, that differential therapies may be developed depending on $P A K 3$ expression level. A therapeutic strategy for tumors with a low $P A K 3$ level could be to target the transcription of $P A K 3$ in order to force post-mitotic cell differentiation by targeting the proneural Notch/Neurogenin/NeuroD pathway previously identified in Xenopus $[8,13,45]$. Differentiation strategies have already been considered for GBM cancer stem cells $[8,34,46]$. However, this approach is complex and requires a more precise description of the function of the gene in different cellular contexts. This was recently illustrated by data showing that the effects of overexpression of $A S C L I$, which acts as a proneural gene during embryonic development and belongs to the proneural signature gene set that includes $P A K 3$, depends on the GBM subtype [47]. Increasing $P A K 3$ expression may be a therapeutic goal in poorly differentiated tumors, since several factors such as neurogenin positively regulate its transcription [48].

We have provided omics and experimental data suggesting a unique role of $P A K 3$ in the pathophysiology of gliomas. These data need to be consolidated by other approaches such as orthotopic grafts of different PDCLs, in which the expression of $P A K 3$ and its kinase activity can be experimentally modified, in order to analyze tumor growth within the brain environment. Our results strongly indicate that each group I-PAK plays a different role in cancer progression, in particular in breast and brain cancer, and that $P A K 3$ acts as a tumor suppressor in gliomas and, as such, may represent a potential therapeutic target.

\section{Grant support}

This work was supported by the Centre National de la Recherche Scientifique (CNRS), the Groupement des Entreprises Françaises dans la Lutte contre le Cancer (GEFLUC, Paris, Ile de France), the Ligue Nationale 
Contre le Cancer (Comité départemental Essonne-Ile de France) and the Association de Recherche sur les Tumeurs Cérébrales (ARTC, France). This work was supported by funding from the Ligue Nationale contre le Cancer (to $\mathrm{EH}$ ), the Association de Recherche sur le cancer (Fondation ARC) (PJA 20,131,200,481 and PJA 20,151,203,259 to EH) and FP7 Marie Curie CIG (to EH). VG is a recipient of a Fondation ARC fellowship. The research leading to these results has received funding from the programs “investissements d'avenir" ANR-10-IAIHU-06 and ANR11-INBS-0011- NeurATRIS: Translational Research Infrastructure for Biotherapies in Neurosciences.

Supplementary Information The online version contains supplementary material available at https://doi.org/10.1007/s13402-021-00635-8.

Acknowledgements We thank OncoNeuroTek for sharing data and samples from their banks. We are also grateful to C. Levasseur for assistance in mice inoculation and to A. Bonilla, C. Dubois and C. Rousseau for animal care. We also acknowledge the technical support from the ICM facility iGenSeq.

\section{Declarations}

Conflict of interest The authors declare no potential conflict of interest

\section{References}

1. S.K. Singh, C. Hawkins, I.D. Clarke, J.A. Squire, J. Bayani, T. Hide, R.M. Henkelman, M.D. Cusimano, P.B. Dirks, Identification of human brain tumour initiating cells. Nature 432, 396 (2004)

2. M. Westphal, K. Lamszus, The neurobiology of gliomas: from cell biology to the development of therapeutic approaches. Nat Rev Neurosci 12, 495 (2011)

3. H.S. Phillips, S. Kharbanda, R. Chen, W.F. Forrest, R.H. Soriano, T.D. Wu, A. Misra, J.M. Nigro, H. Colman, L. Soroceanu, P.M. Williams, Z. Modrusan, B.G. Feuerstein, K. Aldape, Molecular subclasses of high-grade glioma predict prognosis, delineate a pattern of disease progression, and resemble stages in neurogenesis. Cancer Cell 9, 157 (2006)

4. H. Noushmehr, D.J. Weisenberger, K. Diefes, H.S. Phillips, K. Pujara, B.P. Berman, F. Pan, C.E. Pelloski, E.P. Sulman, K.P. Bhat, R.G.W. Verhaak, K.A. Hoadley, D.N. Hayes, C.M. Perou, H.K. Schmidt, L. Ding, R.K. Wilson, D. Van Den Berg, H. Shen, H. Bengtsson, P. Neuvial, L.M. Cope, J. Buckley, J.G. Herman, S.B. Baylin, P.W. Laird, K. Aldape, Identification of a CpG Island Methylator Phenotype that Defines a Distinct Subgroup of Glioma. Cancer Cell 17, 510 (2010)

5. D. Sturm, H. Witt, V. Hovestadt, D.-A. Khuong-Quang, D.T.W. Jones, C. Konermann, E. Pfaff, M. Tönjes, M. Sill, S. Bender, M. Kool, M. Zapatka, N. Becker, M. Zucknick, T. Hielscher, X.-Y. Liu, A.M. Fontebasso, M. Ryzhova, S. Albrecht, K. Jacob, M. Wolter, M. Ebinger, M.U. Schuhmann, T. van Meter, M.C. Frühwald, H. Hauch, A. Pekrun, B. Radlwimmer, T. Niehues, G. von Komorowski, M. Dürken, A.E. Kulozik, J. Madden, A. Donson, N.K. Foreman, R. Drissi, M. Fouladi, W. Scheurlen, A. von Deimling, C. Monoranu, W. Roggendorf, C. Herold-Mende, A. Unterberg, C.M. Kramm, J. Felsberg, C. Hartmann, B. Wiestler, W.
Wick, T. Milde, O. Witt, A.M. Lindroth, J. Schwartzentruber, D. Faury, A. Fleming, M. Zakrzewska, P.P. Liberski, K. Zakrzewski, P. Hauser, M. Garami, A. Klekner, L. Bognar, S. Morrissy, F. Cavalli, M.D. Taylor, P. van Sluis, J. Koster, R. Versteeg, R. Volckmann, T. Mikkelsen, K. Aldape, G. Reifenberger, V.P. Collins, J. Majewski, A. Korshunov, P. Lichter, C. Plass, N. Jabado, S.M. Pfister, Hotspot mutations in H3F3A and IDH1 define distinct epigenetic and biological subgroups of glioblastoma. Cancer Cell 22, 425 (2012)

6. R.G.W. Verhaak, K.A. Hoadley, E. Purdom, V. Wang, Y. Qi, M.D. Wilkerson, C.R. Miller, L. Ding, T. Golub, J.P. Mesirov, G. Alexe, M. Lawrence, M. O'Kelly, P. Tamayo, B.A. Weir, S. Gabriel, W. Winckler, S. Gupta, L. Jakkula, H.S. Feiler, J.G. Hodgson, C.D. James, J.N. Sarkaria, C. Brennan, A. Kahn, P.T, Spellman, R.K. Wilson, T.P. Speed, J.W. Gray, M. Meyerson, G. Getz, C.M. Perou, D.N. Hayes, Integrated genomic analysis identifies clinically relevant subtypes of glioblastoma characterized by abnormalities in PDGFRA, IDH1, EGFR, and NF1. Cancer Cell 17, 98 (2010)

7. M. Vitucci, D.N. Hayes, C.R. Miller, Gene expression profiling of gliomas: merging genomic and histopathological classification for personalised therapy. Br J Cancer 104, 545 (2011)

8. P.-O. Guichet, I. Bieche, M. Teigell, C. Serguera, B. Rothhut, V. Rigau, F. Scamps, C. Ripoll, S. Vacher, S. Taviaux, H. Chevassus, H. Duffau, J. Mallet, A. Susini, D. Joubert, L. Bauchet, J.-P. Hugnot, Cell death and neuronal differentiation of glioblastoma stem-like cells induced by neurogenic transcription factors. Glia 61, 225 (2013)

9. G.M. Bokoch, Biology of the p21-Activated Kinases. Annu. Rev. Biochem. 72, 743 (2003)

10. P. Kreis, J.-V. Barnier, PAK signalling in neuronal physiology. Cell. Signal. 21, 384 (2009)

11. X. Pan, X. Chang, C. Leung, Z. Zhou, F. Cao, W. Xie, Z. Jia, PAK1 regulates cortical development via promoting neuronal migration and progenitor cell proliferation. Mol Brain 8, 36 (2015)

12. M. M. Alves, G. M. Fuhler, K. C. S. Queiroz, J. Scholma, S. Goorden, J. Anink, C. Arnold Spek, M. Hoogeveen-Westerveld, M. J. Bruno, M. Nellist, Y. Elgersma, E. Aronica, and M. P. Peppelenbosch, PAK2 is an effector of TSC1/2 signaling independent of mTOR and a potential therapeutic target for Tuberous Sclerosis Complex. Sci Rep 5, 14534 (2015).

13. J. Souopgui, M. Sölter, T. Pieler, XPak3 promotes cell cycle withdrawal during primary neurogenesis in Xenopus laevis. EMBO J. 21, 6429 (2002)

14. I. Cobos, U. Borello, J.L.R. Rubenstein, Dlx transcription factors promote migration through repression of axon and dendrite growth. Neuron 54, 873 (2007)

15. X. Dai, H. Iwasaki, M. Watanabe, S. Okabe, Dlx 1 transcription factor regulates dendritic growth and postsynaptic differentiation through inhibition of neuropilin-2 and PAK3 expression. Eur J Neurosci 39, 531 (2014)

16. M. R. L. Maglorius Renkilaraj, L. Baudouin, C. M. Wells, M. Doulazmi, R. Wehrlé, V. Cannaya, C. Bachelin, J.-V. Barnier, Z. Jia, B. Nait Oumesmar, I. Dusart, and L. Bouslama-Oueghlani, The intellectual disability protein PAK3 regulates oligodendrocyte precursor cell differentiation. Neurobiology of Disease 98, 137 (2017).

17. M. Radu, G. Semenova, R. Kosoff, J. Chernoff, Pak signaling in the development and progression of cancer. Nat Rev Cancer 14, 13 (2014)

18. R. Kumar, R. Sanawar, X. Li, F. Li, Structure, biochemistry, and biology of PAK kinases. Gene $\mathbf{6 0 5}, 20$ (2017)

19. R. Liu, W. Wang, L. Ye, Y. Bi, H. Fang, B. Cui, W. Zhou, M. Dai, J. Zhang, X. Li, G. Ning, p21-Activated kinase 3 is overexpressed in thymic neuroendocrine tumors (carcinoids) with ectopic ACTH syndrome and participates in cell migration. Endocr 38, 38 (2010) 
20. T. J. Crisman, I. Zelaya, D. R. Laks, Y. Zhao, R. Kawaguchi, F. Gao, H. I. Kornblum, and G. Coppola, identification of an efficient gene expression panel for glioblastoma classification. PLoS ONE 11, e0164649 (2016).

21. A. Venu, B. Archana, R. Kanumuri, V. K. Vuttaradhi, L. D'Cruze, S. Murugan, K. Ganesh, D. Prathiba, M. A. Dymova, S. K. Rayala, and G. Venkatraman, Clinical Evaluation of P21 Activated Kinase 1 (PAK1) Activation in gliomas and its effect on cell proliferation. Cancer Investigation 0, 1 (2020).

22. Y. Zhang, K. Chen, S.A. Sloan, M.L. Bennett, A.R. Scholze, S. O'Keeffe, H.P. Phatnani, P. Guarnieri, C. Caneda, N. Ruderisch, S. Deng, S.A. Liddelow, C. Zhang, R. Daneman, T. Maniatis, B.A. Barres, J.Q. Wu, An RNA-Sequencing transcriptome and splicing database of glia, neurons, and vascular cells of the cerebral cortex. J. Neurosci. 34, 11929 (2014)

23. R2: Genomics Analysis and Visualization Platform (http://r2.amc. $\mathrm{nl}$ http://r2platform.com).

24. L. A. M. Gravendeel, M. C. M. Kouwenhoven, O. Gevaert, J. J. de Rooi, A. P. Stubbs, J. E. Duijm, A. Daemen, F. E. Bleeker, L. B. C. Bralten, N. K. Kloosterhof, B. De Moor, P. H. C. Eilers, P. J. van der Spek, J. M. Kros, P. A. E. Sillevis Smitt, M. J. van den Bent, and P. J. French, Intrinsic Gene Expression Profiles of Gliomas Are a Better Predictor of Survival than Histology. Cancer Research 69, 9065 (2009).

25. A. J. Radenbaugh, S. Ma, A. Ewing, J. M. Stuart, E. A. Collisson, J. Zhu, and D. Haussler, RADIA: RNA and DNA Integrated Analysis for Somatic Mutation Detection. PLoS One 9, (2014).

26. POLA Network, K. Labreche, I. Simeonova, A. Kamoun, V. Gleize, D. Chubb, E. Letouzé, Y. Riazalhosseini, S. E. Dobbins, N. Elarouci, F. Ducray, A. de Reyniès, D. Zelenika, C. P. Wardell, M. Frampton, O. Saulnier, T. Pastinen, S. Hallout, D. Figarella-Branger, C. Dehais, A. Idbaih, K. Mokhtari, J.-Y. Delattre, E. Huillard, G. Mark Lathrop, M. Sanson, and R. S. Houlston, TCF12 is mutated in anaplastic oligodendroglioma. Nat Commun 6, 7207 (2015).

27. S.-N. Bikeye, C. Colin, Y. Marie, R. Vampouille, P. Ravassard, A. Rousseau, B. Boisselier, A. Idbaih, C. Calvo, P. Leuraud, M. Lassalle, S. El Hallani, J.-Y. Delattre, M. Sanson, ASPM-associated stem cell proliferation is involved in malignant progression of gliomas and constitutes an attractive therapeutic target. Cancer Cell Int 10, 1 (2010)

28. S.M. Pollard, K. Yoshikawa, I.D. Clarke, D. Danovi, S. Stricker, R. Russell, J. Bayani, R. Head, M. Lee, M. Bernstein, J.A. Squire, A. Smith, P. Dirks, Glioma stem cell lines expanded in adherent culture have tumor-specific phenotypes and are suitable for chemical and genetic screens. Cell Stem Cell 4, 568 (2009)

29. G. Combeau, P. Kreis, F. Domenichini, M. Amar, P. Fossier, V. Rousseau, J.-V. Barnier, The p21-activated kinase PAK3 forms heterodimers with PAK1 in brain implementing trans-regulation of PAK3 activity. J. Biol. Chem. 287, 30084 (2012)

30. S. Rosenberg, M. Verreault, C. Schmitt, J. Guegan, J. Guehennec, C. Levasseur, Y. Marie, F. Bielle, K. Mokhtari, K. HoangXuan, K. Ligon, M. Sanson, J.-Y. Delattre, A. Idbaih, Multi-omics analysis of primary glioblastoma cell lines shows recapitulation of pivotal molecular features of parental tumors. NEUONC 2, 219 (2016)

31. V. Lamour, A. Henry, J. Kroonen, M.-J. Nokin, Z. von Marschall, L.W. Fisher, T.-L. Chau, A. Chariot, M. Sanson, J.-Y. Delattre, A. Turtoi, O. Peulen, B. Rogister, V. Castronovo, A. Bellahcène, Targeting osteopontin suppresses glioblastoma stem-like cell character and tumorigenicity in vivo. Int. J. Cancer 137, 1047 (2015)

32. S.G.M. Piccirillo, B.A. Reynolds, N. Zanetti, G. Lamorte, E. Binda, G. Broggi, H. Brem, A. Olivi, F. Dimeco, A.L. Vescovi, Bone morphogenetic proteins inhibit the tumorigenic potential of human brain tumour-initiating cells. Nature 444, 761 (2006)
33. M. Ying, S. Wang, Y. Sang, P. Sun, B. Lal, C.R. Goodwin, H. Guerrero-Cazares, A. Quinones-Hinojosa, J. Laterra, S. Xia, Regulation of glioblastoma stem cells by retinoic acid: role for Notch pathway inhibition. Oncogene 30, 3454 (2011)

34. V. Balasubramaniyan, B. Vaillant, S. Wang, J. Gumin, M.E. Butalid, K. Sai, F. Mukheef, S.H. Kim, H.W.G.M. Boddeke, F. Lang, K. Aldape, E.P. Sulman, K.P. Bhat, H. Colman, Aberrant mesenchymal differentiation of glioma stem-like cells: implications for therapeutic targeting. Oncotarget 6, 31007 (2015)

35. C. Neftel, J. Laffy, M.G. Filbin, T. Hara, M.E. Shore, G.J. Rahme, A.R. Richman, D. Silverbush, M.L. Shaw, C.M. Hebert, J. Dewitt, S. Gritsch, E.M. Perez, L.N.G. Castro, X. Lan, N. Druck, C. Rodman, D. Dionne, A. Kaplan, M.S. Bertalan, J. Small, K. Pelton, S. Becker, D. Bonal, Q.-D. Nguyen, R.L. Servis, J.M. Fung, R. Mylvaganam, L. Mayr, J. Gojo, C. Haberler, R. Geyeregger, T. Czech, I. Slavc, B.V. Nahed, W.T. Curry, B.S. Carter, H. Wakimoto, P.K. Brastianos, T.T. Batchelor, A. Stemmer-Rachamimov, M. Martinez-Lage, M.P. Frosch, I. Stamenkovic, N. Riggi, E. Rheinbay, M. Monje, O. Rozenblatt-Rosen, D.P. Cahill, A.P. Patel, T. Hunter, I.M. Verma, K.L. Ligon, D.N. Louis, A. Regev, B.E. Bernstein, I. Tirosh, M.L. Suvà, An integrative model of cellular states, plasticity, and genetics for glioblastoma. Cell 178, 835 (2019)

36. R. Kumar, A.E. Gururaj, C.J. Barnes, p21-activated kinases in cancer. Nat Rev Cancer 6, 459 (2006)

37. P. Kreis, E. Thévenot, V. Rousseau, B. Boda, D. Muller, J.-V. Barnier, The p21-activated kinase 3 implicated in mental retardation regulates spine morphogenesis through a Cdc42-dependent pathway. J. Biol. Chem. 282, 21497 (2007)

38. E. Thévenot, A.W. Moreau, V. Rousseau, G. Combeau, F. Domenichini, C. Jacquet, O. Goupille, M. Amar, P. Kreis, P. Fossier, J.-V. Barnier, p21-activated Kinase 3 (PAK3) protein regulates synaptic transmission through its interaction with the Nck2/Grb4 protein adaptor. J. Biol. Chem. 286, 40044 (2011)

39. M. Lei, W. Lu, W. Meng, M.-C. Parrini, M.J. Eck, B.J. Mayer, S.C. Harrison, Structure of PAK1 in an autoinhibited conformation reveals a multistage activation switch. Cell 102, 387 (2000)

40. M.C. Parrini, M. Lei, S.C. Harrison, B.J. Mayer, Pak1 kinase homodimers are autoinhibited in trans and dissociated upon activation by Cdc42 and Rac1. Mol. Cell 9, 73 (2002)

41. D. Yao, C. Li, M.S.R. Rajoka, Z. He, J. Huang, J. Wang, J. Zhang, P21-Activated kinase 1: emerging biological functions and potential therapeutic targets in cancer. Theranostics 10, 9741 (2020)

42. E. Cerami, J. Gao, U. Dogrusoz, B.E. Gross, S.O. Sumer, B.A. Aksoy, A. Jacobsen, C.J. Byrne, M.L. Heuer, E. Larsson, Y. Antipin, B. Reva, A.P. Goldberg, C. Sander, N. Schultz, The cBio cancer genomics portal: an open platform for exploring multidimensional cancer genomics data. Cancer Discov. 2, 401 (2012)

43. Y. Dang, Y. Guo, X. Ma, X. Chao, F. Wang, L. Cai, Z. Yan, L. $\mathrm{Xie}, \mathrm{X}$. Guo, Systemic analysis of the expression and prognostic significance of PAKs in breast cancer. Genomics 112, 2433 (2020)

44. J.J. Crawford, K.P. Hoeflich, J. Rudolph, p21-Activated kinase inhibitors: a patent review. Expert Opin. Ther. Pat. 22, 293 (2012)

45. R. I. Martinez-De Luna, R. Y. Ku, Y. Lyou, and M. E. Zuber, Maturin is a novel protein required for differentiation during primary neurogenesis. Developmental Biology 384, 26 (2013).

46. M. Santra, S. Santra, B. Buller, K. Santra, A. Nallani, M. Chopp, Effect of doublecortin on self-renewal and differentiation in brain tumor stem cells. Cancer Sci 102, 1350 (2011)

47. A. Narayanan, F. Gagliardi, A.L. Gallotti, S. Mazzoleni, M. Cominelli, L. Fagnocchi, M. Pala, I.S. Piras, P. Zordan, N. Moretta, E. Tratta, G. Brugnara, L. Altabella, G. Bozzuto, P. Gorombei, A. Molinari, R.-A. Padua, A. Bulfone, L.S. Politi, A. Falini, A. Castellano, P. Mortini, A. Zippo, P.L. Poliani, R. Galli, The proneural gene ASCL1 governs the transcriptional subgroup 
affiliation in glioblastoma stem cells by directly repressing the mesenchymal gene NDRG1. Cell Death Differ 26, 1813 (2019)

48. J. Piccand, A. Meunier, C. Merle, Z. Jia, J.-V. Barnier, G. Gradwohl, Pak3 promotes cell cycle exit and differentiation of $\beta$-cells in the embryonic pancreas and is necessary to maintain glucose homeostasis in adult mice. Diabetes 63, 203 (2014)
Publisher's note Springer Nature remains neutral with regard to jurisdictional claims in published maps and institutional affiliations. 
Journal: 13402

Article: $\quad \mathbf{6 3 5}$

\section{Author Query Form}

Please ensure you fill out your response to the queries raised below and return this form along with your corrections

Dear Author

During the process of typesetting your article, the following queries have arisen. Please check your typeset proof carefully against the queries listed below and mark the necessary changes either directly on the proof/online grid or in the 'Author's response' area provided below

\begin{tabular}{|l|l|l|}
\hline Query & Details Required & Author's Response \\
\hline AQ1 & Please check Affiliations if captured correctly. & \\
\hline
\end{tabular}

